Review

\title{
Bacillus thuringiensis Toxins: An Overview of Their Biocidal Activity
}

\author{
Leopoldo Palma ${ }^{1}$, Delia Muñoz ${ }^{2}$, Colin Berry ${ }^{3}$, Jesús Murillo ${ }^{2}$ and Primitivo Caballero ${ }^{1,2, *}$ \\ 1 Instituto de Agrobiotecnología, CSIC-UPNA-Gobierno de Navarra, Campus Arrosadía, \\ Mutilva Baja, 31192 Navarra, Spain; E-Mail: leopoldo.palma@unavarra.es \\ 2 Grupo de Protección Cultivos, Departamento de Producción Agraria, \\ Escuela Técnica Superior de Ingenieros Agrónomos, Universidad Pública de Navarra, \\ Pamplona, 31006 Navarra, Spain; E-Mails: dmunoz@ unavarra.es (D.M.); \\ jesus.murillo@unavarra.es (J.M.) \\ 3 Cardiff School of Biosciences, Cardiff University, Park Place, Cardiff CF10 3AT, UK; \\ E-Mail: Berry@cf.ac.uk
}

* Author to whom correspondence should be addressed; E-Mail: pcm92@ unavarra.es; Tel.: +34-948-168-004; Fax: +34-948-169-300.

External Editor: Anne-Brit Kolstø

Received: 1 September 2014; in revised form: 7 November 2014 / Accepted: 3 December 2014 / Published: 11 December 2014

\begin{abstract}
Bacillus thuringiensis (Bt) is a Gram positive, spore-forming bacterium that synthesizes parasporal crystalline inclusions containing Cry and Cyt proteins, some of which are toxic against a wide range of insect orders, nematodes and human-cancer cells. These toxins have been successfully used as bioinsecticides against caterpillars, beetles, and flies, including mosquitoes and blackflies. Bt also synthesizes insecticidal proteins during the vegetative growth phase, which are subsequently secreted into the growth medium. These proteins are commonly known as vegetative insecticidal proteins (Vips) and hold insecticidal activity against lepidopteran, coleopteran and some homopteran pests. A less well characterized secretory protein with no amino acid similarity to Vip proteins has shown insecticidal activity against coleopteran pests and is termed Sip (secreted insecticidal protein). Bin-like and ETX_MTX2-family proteins (Pfam PF03318), which share amino acid similarities with mosquitocidal binary (Bin) and Mtx2 toxins, respectively, from Lysinibacillus sphaericus, are also produced by some Bt strains. In addition, vast numbers of Bt isolates naturally present in the soil and the phylloplane also synthesize
\end{abstract}


crystal proteins whose biological activity is still unknown. In this review, we provide an updated overview of the known active Bt toxins to date and discuss their activities.

Keywords: Bacillus thuringiensis; Bt biopesticides; toxic activity; Cry toxins; Cyt toxins; Vip toxins; Sip toxins; parasporins

\section{Introduction}

Bacillus thuringiensis $(\mathrm{Bt})$ is a ubiquitous Gram-positive, rod-shaped and sporulating bacterium that has been isolated worldwide from a great diversity of ecosystems including soil, water, dead insects, dust from silos, leaves from deciduous trees, diverse conifers, and insectivorous mammals, as well as from human tissues with severe necrosis [1-4]. Bt strains produce a wide variety of insecticidal proteins active against larvae of very diverse insect orders as well as, in some cases, against species from other phyla. This has led Bt-based products to become the best selling biological insecticides to date [4,5] since the genes encoding insecticidal proteins have been successfully used in novel insecticidal formulations and in the construction of transgenic crops [6].

Bt strains synthesize Crystal (Cry) and cytolytic (Cyt) toxins, (also known as $\delta$-endotoxins), at the onset of sporulation and during the stationary growth phase as parasporal crystalline inclusions (Figure 1). Once ingested by insects, these crystals are solubilized in the midgut, the toxins are then proteolytically activated by midgut proteases and bind to specific receptors located in the insect cell membrane [5,7], leading to cell disruption and insect death.

Figure 1. Protein crystals (bipyramidal) mixed with spores from Bt strain H29.3.

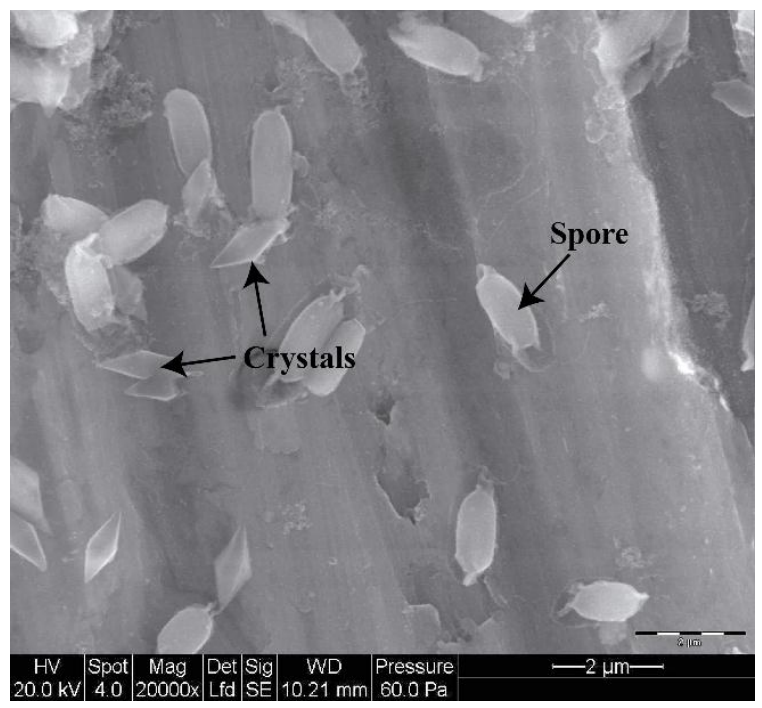

In the past decades, more than 700 cry gene sequences that code for crystal (Cry) proteins have been identified [1,5,8,9] and large plasmids appear to be the usual location for these genes. While many Cry proteins have useful pesticidal properties and may be exploited for the control of insect pests in agriculture (e.g., [10]) other proteins produced as parasporal crystals by Bt strains have no known invertebrate target and have been termed parasporins. Some of this parasporin group of Cry proteins, 
such as Cry31A, Cry41A, Cry45A, Cry46A, Cry63A and Cry64A, exhibit strong and specific cytocidal activity against human cancer cells of various origins and have been given the alternative names parasporin-1 (PS1), parasporin-3 (PS3), parasporin-4 (PS4), parasporin-2 (PS2), parasporin-6 (PS6), and parasporin-5 (PS5), respectively [11,12]. Additionally, Bt isolates can also synthesize other insecticidal proteins during the vegetative growth phase; these are subsequently secreted into the culture medium and have been designated as vegetative insecticidal proteins (Vip) $[13,14]$ and the secreted insecticidal protein (Sip) [15]. Vip proteins are classified into four families Vip1, Vip2, Vip3 and Vip4 according to their degree of amino acid similarity. The binary toxin comprising Vip1 and Vip2 proteins [14] and the Sip toxin [15] exhibit insecticidal activity against some coleopterans, whereas Vip3 toxins are toxic against lepidopterans [15]. The host spectrum of the Vip4Aa1 toxin remains to date unknown.

Bt crystal and secreted soluble toxins are highly specific for their hosts and have gained worldwide importance as an alternative to chemical insecticides. The usefulness of these insecticidal proteins has also motivated the search for new Bt isolates from the most diverse habitats in order to identify and characterize new insecticidal proteins with different specificities. Some of these isolates exhibit novel and unexpected toxic activities against organisms other than insects, suggesting a pluripotential nature of some toxins.

\section{Bt Toxin Nomenclature}

Since the identification and cloning of the first Bt insecticidal crystal protein gene in 1981 [16], the number of genes coding for novel insecticidal proteins has continuously increased, generating the need for an organized nomenclature system. In the first such system, names for Cry toxins and their corresponding genes included a Roman numeral (primary rank distinction) depending on the insecticidal activity of the crystal protein, namely: CryI for proteins toxic for lepidopterans, CryII for proteins with toxicity against both lepidopterans and dipterans, CryIII for proteins toxic for coleopterans; and CryIV for proteins toxic exclusively for dipterans [1]. However, this system exhibited important complications; for instance, the activity of new toxins had to be assayed against a growing list of insects before the gene and the toxin could be named, some novel homologous proteins were in fact non-toxic as expected, and others (e.g., Cry1I) exhibited dual toxicity against dipteran and lepidopteran species [17]. To avoid these problems, the Bacillus thuringiensis Toxin Nomenclature Committee was created and a novel system of classification proposed [8,17]. In this new system, a novel toxin is given a four-rank name depending on its degree of pairwise amino acid identity to previously named toxins; additionally, grouping by this criterion does not imply a similar protein structure, host range or even mode of action. Arabic numbers are used for the first and fourth ranks, and uppercase and lowercase letters are assigned for the second and third ranks, respectively (Figure 2). In this way, proteins sharing less than $45 \%$ pairwise identity are assigned a different primary rank (an Arabic number, e.g., Vip1 and Vip2); two proteins sharing less than 78\% pairwise identity are assigned a different secondary rank (a capital letter, e.g., Vip3A and Vip3C); proteins sharing less than $95 \%$ pairwise identity are assigned a different tertiary rank (a lowercase letter, e.g., Vip3Aa and Vip3Ab); and, finally, to differentiate between proteins sharing more than 95\% pairwise identity, a quaternary rank is assigned (an Arabic number, e.g., Vip3Aa1 and Vip3Aa2) [8,17]. 
However, such quaternary ranks are assigned to each independently sequenced toxin-coding gene; therefore, although some proteins may have different quaternary ranks, they could actually share identical amino acid sequences [8]. This nomenclature system is commonly applied to $\delta$-endotoxins (Cry and Cyt) and secretable (Vip and Sip) Bt toxins.

Figure 2. Schematic overview of the current nomenclature system used by the Bt Toxin Nomenclature Committee for $\delta$-endotoxins (Cry and Cyt) and secretable (Vip and Sip) toxins [8]. In this example, numbers indicate different Vip proteins changing rank 1 depending of percentage amino acid similarity (for Vip proteins this rank may change to date among Vip1, Vip2, Vip3 and Vip4). The same rule applies for ranks 2, 3 and 4 assigning a different identification digit/letter.

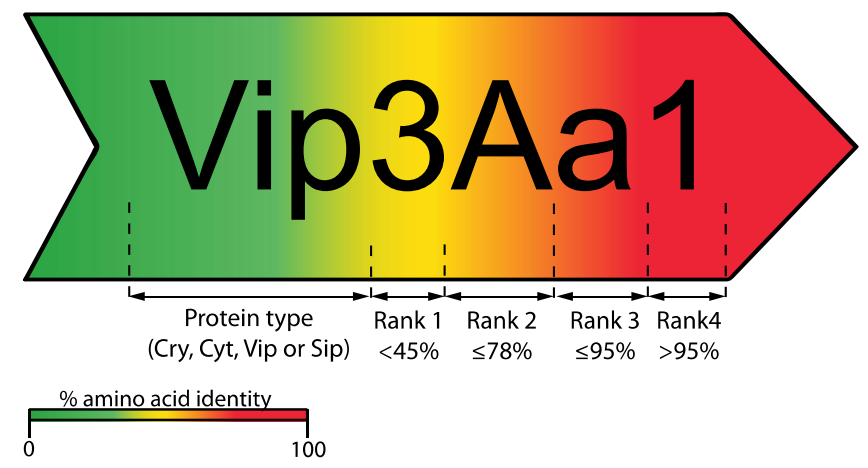

\section{Crystal Toxins ( $\delta$-endotoxins)}

Crystal proteins are formed as parasporal crystalline inclusions during the stationary phase of growth $[1,5]$. The most widely known are the $\delta$-endotoxins, including Cry and Cyt toxins. Cry proteins can be sub-divided into groups according to their homology and molecular structure. As mentioned above, crystal toxins with no known invertebrate activity have both Cry and Ps designations [12]. These proteins belong to either the three-domain (Cry31 or Ps1, Cry41 or Ps3, Cry63 or Ps6) or the ETX_MTX2 family proteins (Cry45 or Ps4, Cry46 or Ps2, Cry64 or Ps5) and exhibit strong and specific cytocidal activity against human-cancer cell lines (upon protease activation) [11].

The Cyt proteins constitute a smaller, distinct group of crystal proteins with insecticidal activity against several dipteran larvae, particularly mosquitoes and black flies [7,18-22]; additionally, some Cyt toxins are capable of synergizing the insecticidal activity of other Bt proteins [22,23].

\subsection{Cry Toxins}

The naming of a protein as a Cry toxin derives from the fact that it forms a parasporal crystal. As a result, Cry toxins do not belong to a single, homologous family of proteins but, instead, include a number of unrelated lineages. The largest group comprises the well-known three-domain Cry proteins, whereas other Cry toxins belong to distinct protein families e.g., binary Bin- and ETX_MTX2-like toxins produced by Lysinibacillus sphaericus (Ls, formerly known as Bacillus sphaericus) [21,24] as described below.

Currently, the Cry proteins constitute the largest group of insecticidal proteins produced by species of Bacillus. To date, the Bt Toxin Nomenclature Committee [8] has classified 73 different types 
(Cry1 to Cry73) of Cry proteins, including three-domain and ETX_MTX2 family proteins from Bt and Ls, with individual toxins showing well documented toxicity against lepidopterans, coleopterans, hemipterans, dipterans, nematodes (human and animal parasites, and free living; Rhabditida) some snails [1,5,9,18,21,25-28] and/or human-cancer cells of various origins [11,12] (Figure 3).

Figure 3. Summarized view showing the known host spectrum of $\mathrm{Bt} \delta$-endotoxins (Cry and Cyt) $[9,26]$. Cry1A-C (separated by hyphen) indicates a group of C3y1A, Cry1B and Cry1C toxins. Cry1B, I (separated by colon) indicates different Cry1B and Cry1I toxins. Semicolons separate groups or individual toxins. Cyt toxins are in red.
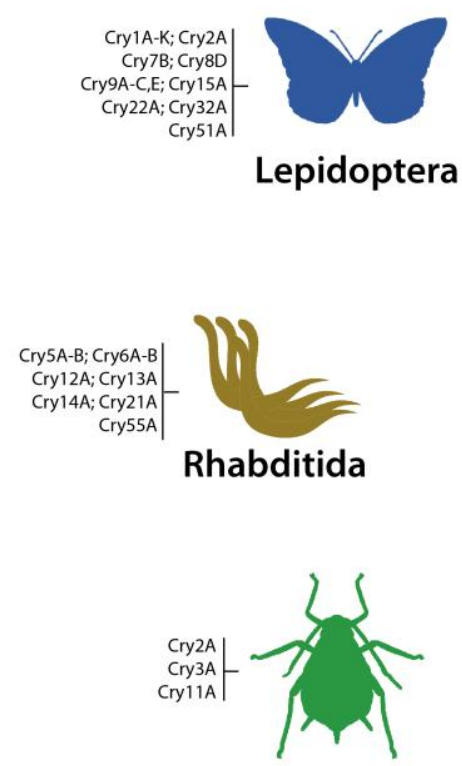

Hemiptera

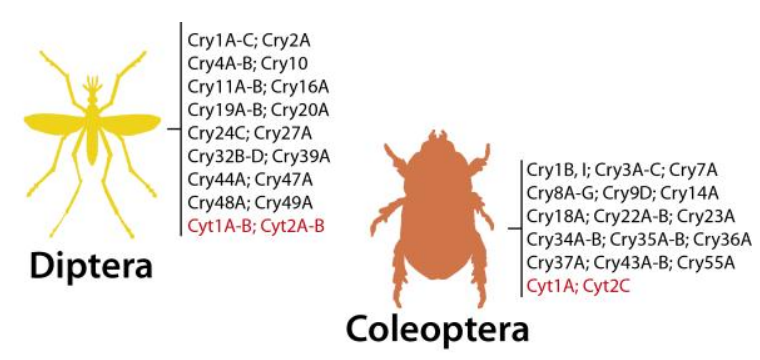

¿-Endotoxins
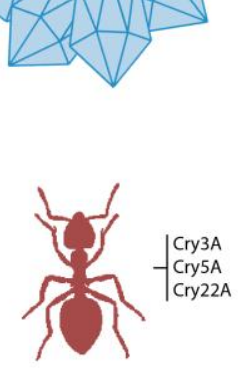

Hymenoptera

Some Cry proteins may be responsible for other novel toxic properties. Bt strains B622 and B626, isolated in Japan, produced parasporal crystal proteins exhibiting activity against the human pathogenic protozoan Trichomonas vaginalis as well as producing lectin-like effects (agglutination) on rabbit erythrocytes [29]; however, they did not show any insecticidal effect against the lepidopteran Plutella xylostella and the dipteran Culex pipiens molestus [30]. Additionally, the crystal proteins produced by Bt strains 977 and NRRL HD-522 displayed moderate but specific molluscicidal activity against Chinese Oncomelia snails [27,31], the intermediate host of the trematode worm Schistosoma japonicum, the cause of endemic schistosomiasis in China and The Philippines [32].

Certain crystal toxins show also undesirable activities, such as the haemolytic activity described for Cry15A toxin [33]. Finally, other Cry toxins have also shown antibacterial activity. This is of great relevance for the $\mathrm{Bt}$ community because procedures to evaluate the insecticidal activity of crystal proteins generally involve their expression in E. coli to obtain pure proteins, and a potential antibacterial activity might hamper their cloning and/or adequate expression (e.g., the three-domain toxins Cry13A and Cry14A) [34]. Additionally, when supplied exogenously, the B. thuringiensis subsp. israelensis toxins Cyt1Aa, Cry4Ba and Cry11Aa are bactericidal or bacteriostatic to E. coli and three Gram-positive bacterial species, whereas Cry1A, Cry3A and a CryD-like toxin, produced by 
other Bt subspecies, displayed antibacterial activity upon proteolytic activation against species of the anaerobic Gram-positive genus Clostridium and to an archaeal species [18,35-37]. Other Cry and Cyt-like sequences have also been reported to be bactericidal [35-37].

\subsubsection{Three-Domain Cry Toxins}

Cry toxins belonging to the three-domain Cry toxin family, display clear differences in their amino acid sequences but all share in common a remarkably similar and conserved three-domain structure [7,21,38,39] (Figure 4).

Figure 4. Three-dimensional structure of Cry2Aa toxin. This structure from PDB accession number $1 \mathrm{I} 5 \mathrm{P}$ [40], is representative of a three-domain toxin produced by Bt. Roman numerals indicate the typical domains of the three-domain Cry proteins: (I), perforating domain; (II), central domain, involved in toxin-receptor interactions; (III), galactose-binding domain, involved in receptor binding and pore formation $[7,21,38,39]$.

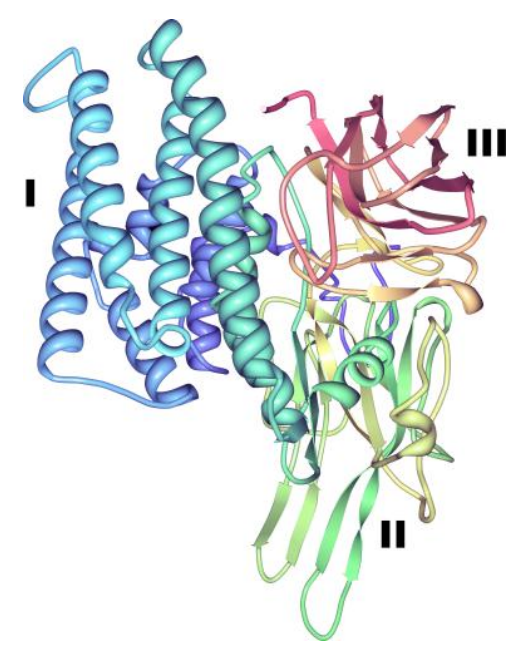

Domain I or perforating domain, located towards the $N$ terminus, is constituted by a seven $\alpha$-helix cluster that is subjected to proteolytic cleavage in all three-domain Cry proteins during toxin activation (Figure 4) and this may be responsible for toxin membrane insertion and pore formation $[5,18,41]$. Domain II (central or middle domain) consists of three antiparallel $\beta$-sheets and plays an important role in toxin-receptor interactions [41,42]. Lastly, domain III (galactose-binding domain), which is proteolytically cleaved in some three-domain Cry proteins, is a two antiparallel $\beta$-sheet sandwich that is also involved in receptor binding and pore formation [41]. A recent paper has revealed the structure of the protoxin form of Cry1Ac [43] (PDB accession number 4W8J), demonstrating that the toxin region is already folded into the three-domains while the extended pro-region forms a further 4 domains. Domains IV and VI are alpha helical, whereas domains V and VII have a beta roll topology and in the dimer seen in the packing of the crystals, the toxic region of one monomer is cradled by the pro-region of the other. Although the proCry1Ac used in these studies was mutated to remove 14 of the 16 cysteine residues in order to facilitate the experiments, observation of the natural location of these residues in the protoxin structure gives indications of the likely disulphide cross-linking that stabilizes the natural Bt crystals [44]. Such inter-molecular disulphide bonds are more labile than 
intra-molecular bonds [45] and are labile under acid and alkaline conditions, explaining the solubilization of $\mathrm{Bt}$ toxins in the environment of the insect gut. Multiple-sequence alignments of different Cry toxins also revealed the presence of up to five typical conserved blocks located in the active toxic core of the protoxins (domains I, II and III) which is released after protein activation by midgut proteases [1] and three additional conserved amino acid blocks lying outside this active core and towards the $C$-terminal end of the protoxin (Figure 5). Several of the three-domain protoxins (e.g., Cry3 and Cry11 toxins) lack the extended $C$-terminal region and are, instead, synthesized as shorter protoxins of approximately 70-kDa.

Figure 5. Amino acid conserved blocks (1 to 8) among different three-domain Cry proteins (colored boxes) [5]. Green boxes represent the five conserved amino acid blocks first described by Höfte and Whiteley located in the Cry protein toxic core [1]. Red boxes indicate the three additional conserved amino acid blocks found by Schnepf et al. [5]. The protoxin is digested by midgut proteases into a smaller fragment, which is responsible for toxic activity. Three-dimensional structure changes upon proteolytic activation are also depicted for Cry1Ac protoxin: toxic core comprising domains I, II and III (boxed), domain IV (cyan), domain V (blue), domain VI (green), and domain VII (red) [43].

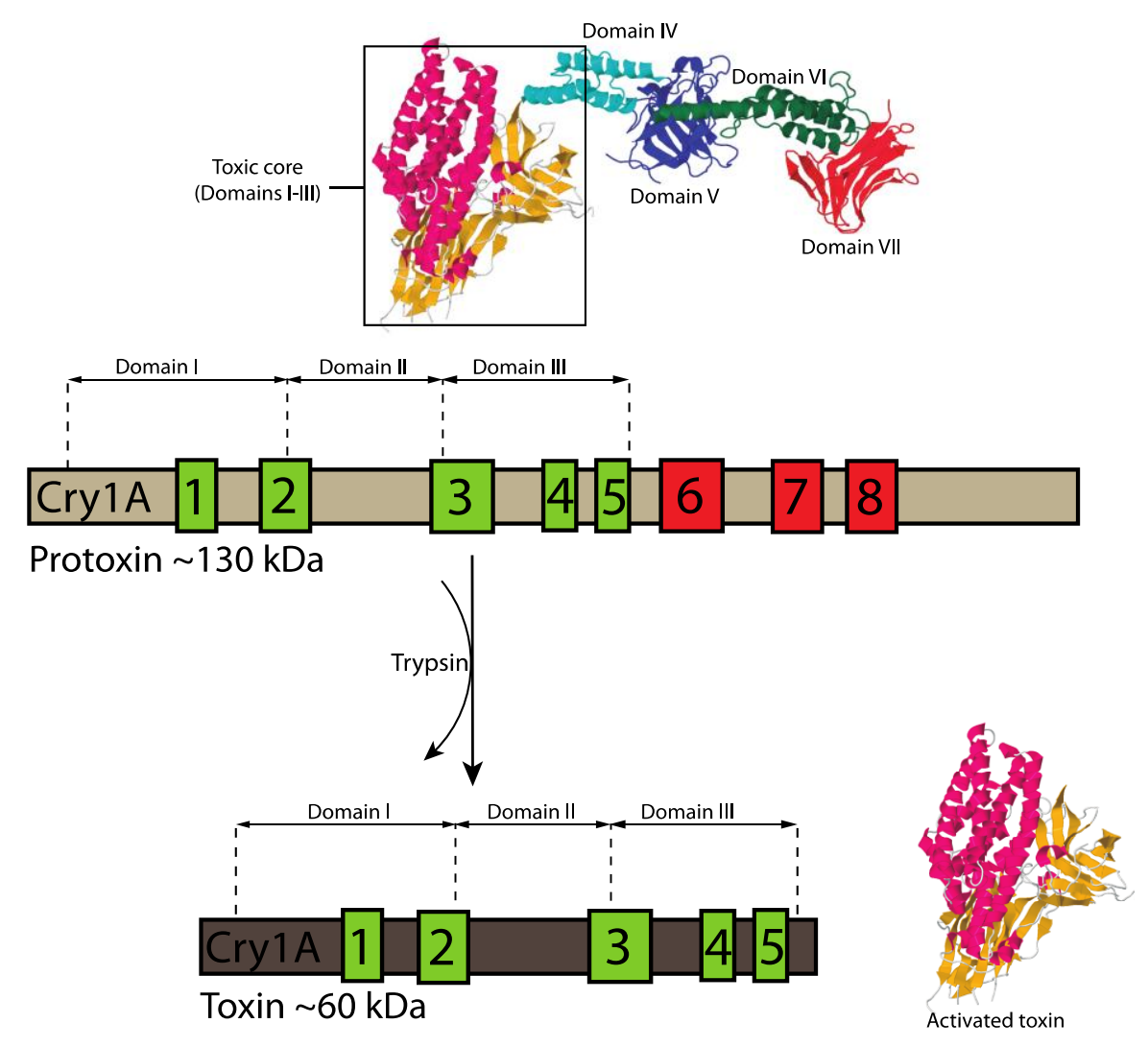

Bt three-domain Cry proteins display toxic activity against insect species of the following orders: Lepidoptera, Diptera, Coleoptera, Hemiptera (low to moderated toxicity for some aphids) and nematodes $[9,26]$.

The mode of action of three-domain crystal proteins has been studied mainly in lepidopteran insects [7]. Three different models have been proposed to explain the mode of action of three-domain Cry toxins: the "classical" model, the sequential binding model and the signaling pathway model [46]. The "classical" 
model basically proposes that the toxin lyses the midgut epithelial cells of susceptible insects throughout the following steps: (a) crystal inclusion ingestion and dissolution in the alkaline midgut lumen; (b) protoxin (native protein) proteolytic activation that turns the native Cry protein into smaller protease-resistant toxic polypeptides; (c) binding of toxin fragments to specific receptors on the surface of midgut epithelial cells; and (d) formation of non-selective pores permeable to inorganic ions, amino acids and sugars [46,47]. Such pores produce the lysis of epithelial cells and hence midgut disarrangements, leading to insect death. Additionally, spores may colonize, germinate, and replicate in the hemolymph, eventually killing larvae by septicemia [1,2,5]. Although this scheme has been accepted for many years, some details still remain poorly understood (e.g., pore structure and mechanism of pore assembly) [46]. The sequential binding model suggests that Cry toxins, once activated by intestinal proteases, bind to cadherin-like proteins (transmembrane glycoproteins that function as toxin receptors) and undergo a conformational change that favors proteolytic removal of the $\alpha-1$ helix from domain I and formation of an oligomeric pre-pore structure. Later, binding to a secondary receptor, such as an aminopeptidase, facilitates the insertion of the pre-pore structure into the membrane, leading to cell and insect death $[7,39]$. In contrast, the signaling-pathway model suggests that the toxic activity is mediated by the specific binding to cadherin receptors, leading to undescribed $\mathrm{Mg}^{2+}$-dependent and adenylyl cyclase/protein kinase A signaling pathway that produces necrotic cell death [48]. Vachon et al. (2012) have recently reviewed experimental evidence supporting both the sequential binding and the pathway-signaling models [46]. These authors concluded that both models, and more importantly the sequential binding model, are supported by little reliable experimental evidence and that the present available information supports the "classical" model postulating that Cry toxins act by forming pores, although most events leading to their formation and receptor binding remain still poorly understood [48]. While cadherins and amino peptidases frequently emerge as candidates in Cry toxin binding [49], a number of other potential receptors have been proposed including alpha amylases and alpha glycosidases [50,51], prohibitin [52] and alkaline phosphatases [53,54]. The precise role of multiple putative receptors identified for individual toxins is, as yet, unclear.

\subsubsection{Non-Three-Domain Cry Toxins}

In addition to the major family of three-domain Cry toxins, several other families of unrelated toxins are covered by the Cry nomenclature. Despite a low level of primary sequence identity, which leads them to be classified under distinct primary rankings in the nomenclature, Cry15, Cry23, Cry33, Cry38, Cry45 (parasporin 4), Cry51, Cry60 and Cry64 all show features of the ETX_MTX2 family that includes the Mtx2 protein from Ls and the Clostridium epsilon toxin. The latter toxin has an extended beta sheet structure related to aerolysin, a pore-forming toxin produced by the Gram-negative bacterium Aeromonas hydrophila and other related species [55,56], and forms beta-barrel pores in target cells [57]. A similar mode of action is also likely for the Cry toxins above.

Other toxins belong to the Toxin_10 family of proteins and include Cry35 and Cry36 from Bt (in addition to BinA, BinB and Cry49 from Ls). The recently published crystal structures of Cry35Ab1 [58] and BinB [59] show these proteins also to have an aerolysin-like fold. Cry35 has a beta trefoil $\mathrm{N}$-terminal domain containing QxW motifs similar to those found in carbohydrate-binding domains in proteins, such as ricin and Mtx1 from Ls (Figure 6). 
Figure 6. Three-dimensional structure of binary Cry34/Cry35 toxin from PDB accession numbers 4JOX (Cry34) and 4JPO (Cry35) [58]. QxW motifs are depicted as colored residues: red-blue-red and red-cyan-red at positions Q89-K90-W91 and Q133-Q134-W135, respectively, located at the $N$-terminal domain (gray).

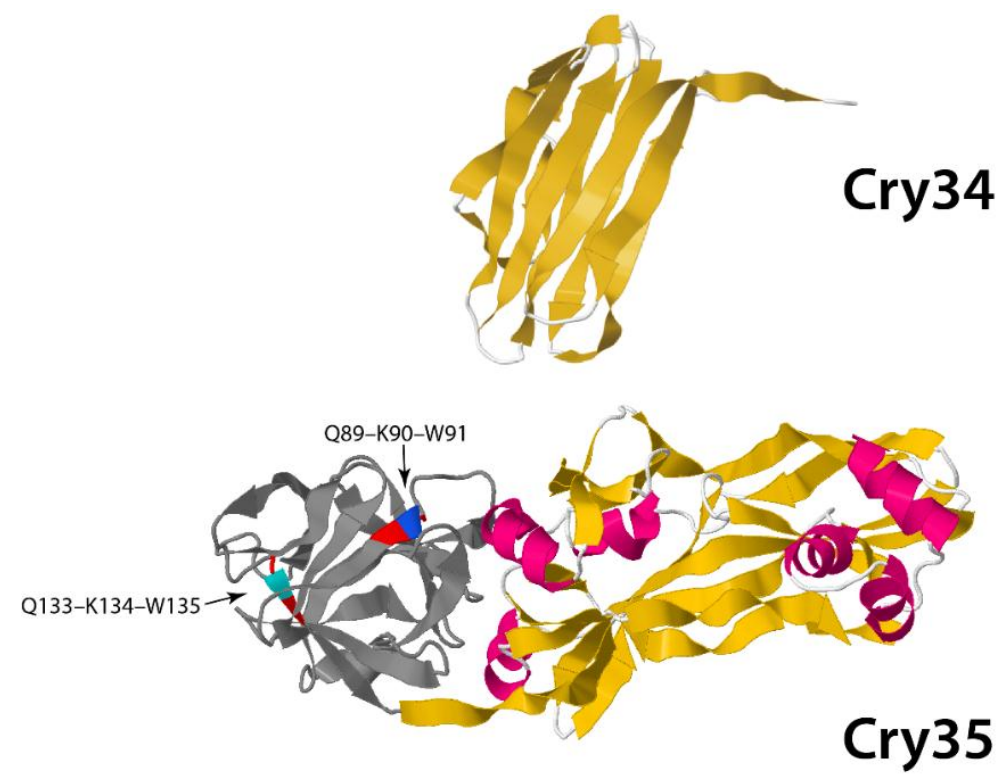

The rest of the molecule is dominated by an extended beta sheet structure, mirroring that of aerolysin. The crystal structures of Cry45 (Ps4), Cry46 (Ps2) and Cry23 [21,60,61] also show aerolysin folds. Thus, the Toxin_10 group of proteins along with Cry23, Cry45 and Cry46 may also represent beta pore forming toxins, sharing aerolysin as a structural homolog with the ETX_MTX2 family. It is interesting to note that some of the above toxins are able to act alone to cause toxicity (e.g., Cry36), whereas others require a second protein to act as binary toxins (e.g., BinA/BinB, Cry23/Cry37, Cry34/Cry35, Cry48/Cry49) [21,62].

Cry34 is a member of the aerolysin family, which has known interactions with membranes. Its recently published structure [58] (PBD accession number 4JOX) shows a single domain protein with a beta-sandwich conformation and a hydrophobic core (Figure 6). It is interesting to note that, although there is no obvious homology at the level of their amino acid sequences, the Cry34/Cry35 pair show remarkable structural similarity to another binary toxin, Cry23/Cry37 [21]. The precise interactions by which these binary toxins elicit their activity against coleopteran targets remains to be elucidated.

Another non-three-domain protein, Cry22 is reported to show 4 cadherin-like domains and a $C$-terminal region with structural similarities to domain III of the three-domain toxins [21]. No structural data are available for the Cry6 proteins, which show features of the Smc chromosome segregation protein family within their central regions. Studies of the mechanisms of action of these proteins are limited $[63,64]$ and the possible roles of these features are unknown. Cry55 also has no known structural homologs and shows no conserved domains and, as a result, its mode of action also remains unclear. 


\subsection{Cyt Toxins}

Cyt (cytotoxic) proteins, coded for by cyt genes, constitute another relevant insecticidal protein family in Bt [65]. In contrast to Cry proteins, Cyt proteins exhibit a general cytolytic (hemolytic) activity in vitro and predominantly dipteran specificity in vivo [19,21]. The three-dimensional structures of the Cyt1Aa [20] and Cyt2Ba [66] show these proteins to be single domain, three-layer alpha-beta proteins (Figure 7).

Figure 7. Three-dimensional structure for toxin Cyt1Aa and activated Cyt2Ba monomer from PDB accession numbers 3RON [20] and 2RCI [66], respectively.

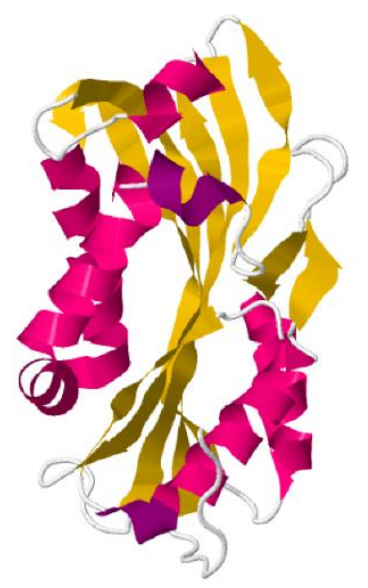

Cyt1Aa

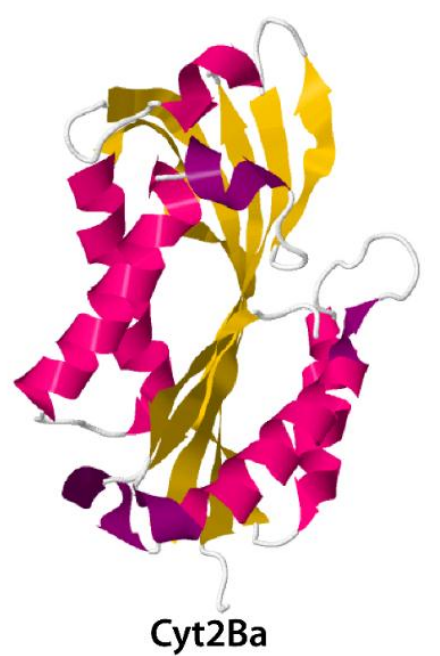

Cyt2Ba

The Cyt1Ca protein encoded by the pBtoxis plasmid of Bt subsp. israelensis [67] is different in having a further domain with homology to the carbohydrate binding domain of ricin, attached to the $C$-terminal end of the Cyt domain but no larvicidal or hemolytic activity has been observed with this toxin [68]. To date, the Bt Toxin Nomenclature Committee [8] has classified Cyt proteins into three different families (Cyt1, Cyt2 and Cyt3; primary rank) with toxicity mostly against some mosquitoes and black flies [22]. However, some strains of diverse Bt subspecies, e.g., subsp. morrisoni, bear cyt genes with toxic activity against a wider range of insects, including Diptera, Lepidoptera and Coleoptera [65]. It has also been reported that Cyt2C may be active against nematodes (Rhabditida) and cancer cells [9]. Another interesting feature of Cyt proteins is their ability to synergize the insecticidal activity of other Cry or Vip3 toxins and to reduce levels of insect resistance to some Cry proteins in some insect species [22,23]. For instance, Cyt1Aa toxin is active against Chrysomela scripta and inhibits the development of resistance to Cry3Aa [69]. Similarly, Cyt1Aa is able to suppress resistance to Cry4 and Cry11Aa toxins in larvae of laboratory selected Culex quinquefasciatus populations [22]. Binding of Cry11Aa to Cyt1Aa facilitates both the oligomerization of Cry11Aa toxin and pore formation, and has been proposed as the mechanism leading to synergism [22]. Moreover, toxins Cyt $1 \mathrm{Ab}$ and Cyt2Ba from Bt subsp. medellin and subsp. israelensis enhanced the insecticidal activity of Ls against Aedes aegypti and resistant C. quinquefasciatus larvae [70]. Cyt1Aa has also been demonstrated to have a synergistic activity, when combined with Mtx1 toxin from Ls, against $C$. quinquefasciatus [71]. Two different modes of action have been proposed for the Cyt group of proteins: one suggests a pore-formation model, 
whereas the other supports a less specific detergent action mechanism [19,21,22]. For toxins like Cyt1Aa, with a typical cytolysin fold and a specific hemolytic pattern that differs from ionic and non-ionic detergents, a pore-forming mechanism was further suggested [20].

\section{Secreted Toxins}

During the vegetative growth phase of $\mathrm{Bt}$, some strains produce proteins that are secreted into the medium and have been found to have insecticidal properties against a number of insects, extending the overall host range of this bacterium $[5,72,73]$. The secreted insecticidal proteins constitute two classes that were designated as vegetative insecticidal proteins (Vip) $[8,13,14]$ and secreted insecticidal protein (Sip) [15]. Currently, the Bt Toxin Nomenclature Committee [8] has identified and classified Vip proteins into four different families namely Vip1, Vip2, Vip3 and a novel family of Vip proteins, recently identified and classified as Vip4 by the Bt Toxin Nomenclature Committee [8]. Bt secretable proteins like Vip1, Vip2 and Sip, contain conserved signal peptide sequences that are commonly cleaved before or after the secretion process is completed [13-15,21,74]. Vip1 and Vip2 constitute a binary toxin with high insecticidal activity against some coleopteran pests [14] and the sap-sucking insect pest Aphis gossypii (Hemiptera) [75]. In contrast, Vip3 proteins are single-chain (not binary) toxins with insecticidal activity against a wide variety of lepidopteran species [13].

\subsection{Vip1/Vip2 (Binary) Toxins}

The Vip1 and Vip2 proteins together constitute a binary toxin. The vip1 and vip2 genes are co-transcribed from a $\sim 4-\mathrm{kb}$ single operon and encode $\sim 100$ and $\sim 50-\mathrm{kDa}$ proteins, respectively [21,76]. They were initially discovered from $\mathrm{Bc}$ strain $\mathrm{AB} 78$ and $\mathrm{Bt}$ in the 1990s [14,21,74,77]. Vip1 and Vip2 contain typical Bacillus $N$-terminal signal peptide sequences and Vip1 is $N$-terminally processed after secretion into a smaller $\sim 80-\mathrm{kDa}$ mature protein. Vip1/Vip2 showed toxic activity against some coleopteran larvae (e.g., Diabrotica spp.) and the sap-sucking insect pest Aphis gossypii (Figure 8) [14,21,75]. Their homology to other bacterial binary toxins suggests that Vip1 and Vip2 form typical A+B type binary toxins, where Vip2 is the cytotoxic A-domain and Vip1 the receptor-binding domain responsible of the translocation of the cytotoxic Vip2 into the host cell $[21,77]$. Vip2 exhibits sequence and structural homology with the enzymatic domain of toxin CdtA from Clostridium difficile and the iota-toxin domain Ia from $C$. perfringens, both possessing ADP-ribosyltransferase activity that targets actin, inducing cytoskeletal disorders and cell death [77,78]. The crystal structure of Vip2 from $\mathrm{Bc}$ in apo and $\mathrm{NAD}^{+}$complexed form is consistent with this mechanism of action [78]. The proposed mechanism of action involves the proteolytic activation of the cell-binding B precursor (Vip1) and its monomeric interaction with cell surface receptor(s) followed by formation of homoheptamers that subsequently translocate the A (Vip2) toxic component into the cytoplasm through acid endosomes [77]. Once inside the cytoplasm, the A component destroys filamentous actin, likely by mono-ADP-ribosylation of the Arg177 residue of G-actin, blocking its polymerization and leading to cell death by cytoskeletal disarrangement $[74,79]$. 
Figure 8. Schematic tree showing the distribution and known host spectrum of different secreted Bt toxins namely Sip1 protein, toxic for some Coleoptera [15], Vip1/Vip2 (binary) toxins active against Coleoptera [14] and Hemiptera [75], Vip4 unknown toxicity and host range [8] and Vip3 toxins active against Lepidoptera [13].

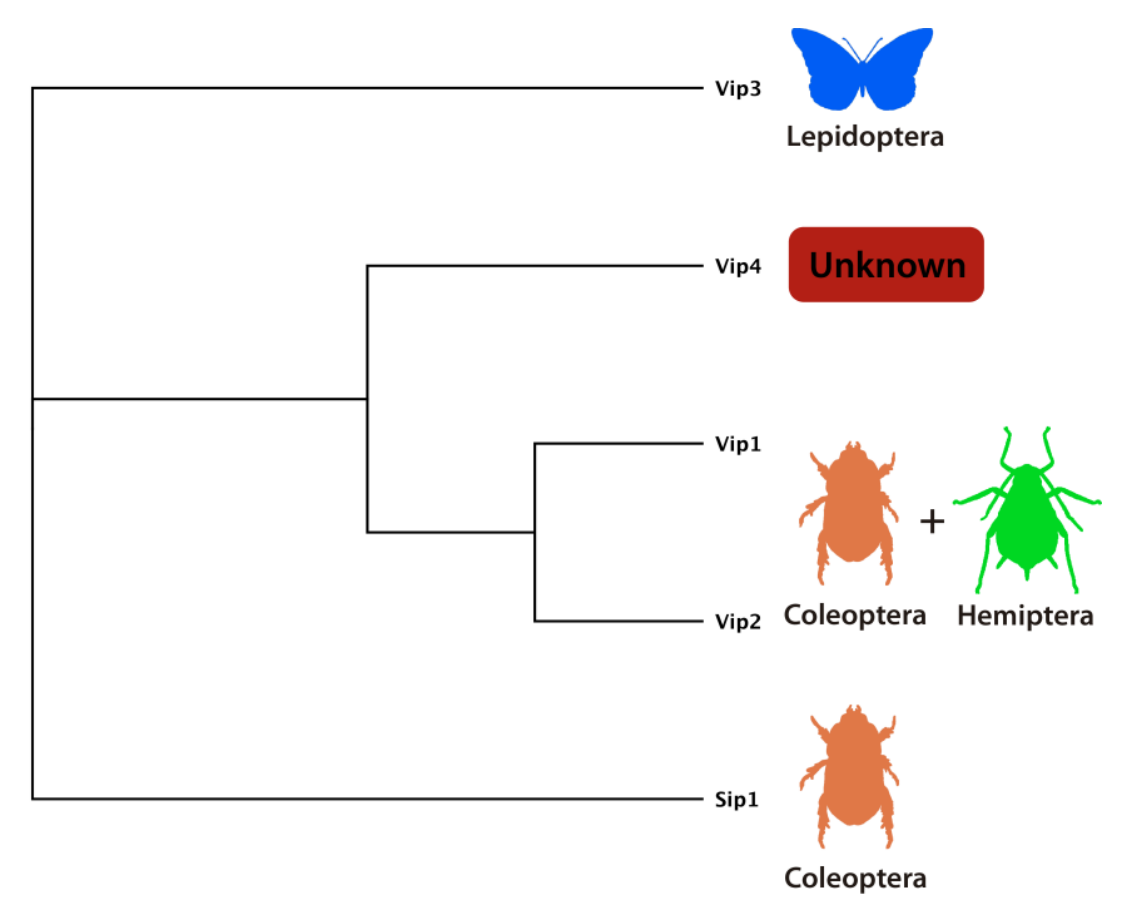

\subsection{Vip3 Proteins}

The first vip3 genes were originally cloned from total DNA libraries of Bt strains AB88 and AB424 and were designated as vip3Aal and vip3Abl [13], respectively. They encode 791-aa proteins (88.5-kDa) and show no homology to any other known insecticidal protein [13,21].

Vip3A proteins exhibit insecticidal activity against a wide variety of lepidopterans and, interestingly, certain species less susceptible to some Cry1A proteins (e.g., Agrotis ipsilon, Spodoptera exigua and S. frugiperda) $[13,80]$. To date, there are three different subfamilies of Vip3 proteins that were designated Vip3A [13], Vip3B [81] and Vip3C [82] (Figure 8). In contrast with Vip1 and Vip2, Vip3 proteins contain conserved but non-typical signal peptide sequences that are not processed during secretion and are present in the secreted mature peptide $[13,21,83]$. Treatment of Vip3Aa1 with midgut fluids from susceptible insects or trypsin releases four major protein products with molecular weights of approximately 22, 33, 45, and 66-kDa [84]. The 66-kDa fragment is separated from the $22-\mathrm{kDa} \mathrm{N}$-terminal portion and is known as the activated "trypsin resistant core". This processed portion of Vip3 proteins, which is the major polypeptide fraction that retains toxicity, may vary in size from 62 to 66-kDa [84,85], and remains highly conserved between different Vip3 proteins. When this activated fragment was cloned and expressed in E. coli, no toxicity was observed against insect species previously found to be susceptible, suggesting that the 22-kDa $N$-terminal portion is necessary for toxicity or folding $[13,21,83]$. Preliminary analysis of the structure of the Vip3Ag4 protoxin by electron microscopy, strongly suggests that molecules of the protein may be grouped together forming a tetrameric structure [86]. While there is evidence that Vip3 proteins act by pore formation [87], the mode of action of Vip3 proteins remains poorly understood. A proposed 
mechanism suggests that activated Vip3A toxin binds to the midgut epithelial cells of susceptible insects causing their lysis, gut paralysis and larval death $[21,88]$. It has been suggested that this mode of action differs from that of some Cry1A toxins, at least with respect to receptor binding and ion channel properties. Indeed, Vip and Cry proteins do not compete for binding sites in the lepidopterans Manduca sexta and S. frugiperda [87,89]. Additionally, extensive in vitro and in vivo studies have shown very low levels of cross-resistance between Vip3A and Cry1 proteins [85,90,91]. These Vip3 properties open the possibility to use Bt-based biopesticides for a greater number of pests and for the management of emerging insect resistance events to Bt Cry proteins [89,92,93].

\subsection{Vip4 Protein}

A novel protein has been identified by Sun et al. (2010) and designated Vip4Aa1 (Figure 9) [8]. The vip4Aal gene is 2895 bp long with a deduced amino acid sequence of 965 residues and predicted molecular weight of $\sim 108-\mathrm{kDa}$. Its predicted protein sequence exhibited $34 \%$ and $65 \%$ pairwise identity to Vip1Aa1 protein and the Iota toxin $\mathrm{Ib}$ from $\mathrm{Bc}$, respectively. Protein sequence analysis detected a putative signal peptide sequence plus two conserved domains: an anthrax protective antigen PA14 domain (InterPro family IPR011658) and a bacterial Binary_ToxB exotoxin domain (InterPro family IPR003896) commonly found in binary Vip1 and other related bacterial toxins (Figure 9). The insecticidal properties (activity and host range) of this protein remain unknown, although Vip4Aa1 seems to be phylogenetically more closely related to Vip1 proteins (Figure 8) than to the other two Vip groups (Vip2 and Vip3) [8]. Since it resembles the B component of a binary toxin, it is possible that Vip4 interacts with an, as yet, unidentified A component, perhaps a Vip2, to elicit toxicity. A further possibility is that it is a B-component that has lost its A-component and can no longer confer toxicity. Analysis of the genome of strain Sbt016, from which Vip4 was identified, may shed some light on these questions.

Figure 9. Predicted features and conserved domains found in Vip4Aa1 toxin. SP: predicted signal peptide (residues 1-28), PA14: conserved domain (residues 45-179), Binary_toxB: conserved domain (residues 218-631) commonly found in Vip1Aa1 proteins and present in novel Vip4Aa1 toxin.

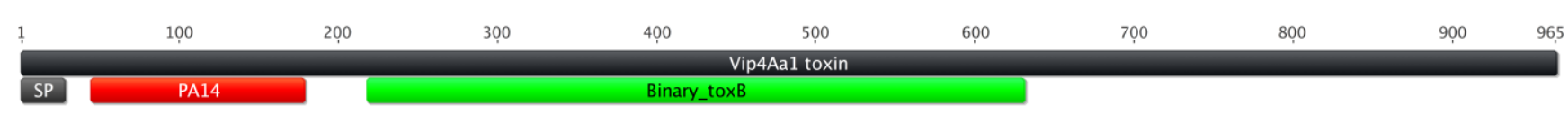

\subsection{Sip Toxin}

The secreted insecticidal protein (Sip) constitutes the first and only member of a Bt insecticidal family of secreted proteins with demonstrated toxicity against coleopteran larvae. Sip protein was initially obtained from culture supernatants of the Bt strain EG2158 and was designated as Sip1Aa1 [15]. The siplAal gene is 1104 bp long and encodes a protein of 367 amino acids and 41-kDa. Sip1 Aa1 exhibits typical predicted Gram-positive consensus secretion signal 30 amino acids long. However, the protein was found $N$-terminally processed, with its first 43 amino acids eliminated by active proteases present in the culture medium. It shows low but significant similarity to the $36-\mathrm{kDa}$ Mtx3 mosquitocidal toxin (a member of the ETX_MTX2 family of toxins) from Ls. This homology 
strongly suggests that Sip1Aa1 toxicity may be caused by pore formation, but its mode of action remains unknown [15]. Sip1Aa1 is lethal for Leptinotarsa decemlineata (Coleoptera: Chrysomelidae) and inhibits growth of Diabrotica undecimpunctata howardi (Coleoptera: Chrysomelidae) and D. virgifera virgifera [15]. Although Sip1Aa1 is the only protein reported to date with published insecticidal activity against these insects, several other homologs with at least $90 \%$ pairwise identity have been published as hypothetical proteins in public databases (e.g., GenBank accession number WP_000875422).

\section{Other Potential Insecticidal Toxins}

Bt also synthesizes other proteins, the sequences and conserved domains of which suggest that they may be toxic agents but which have received little investigation. In addition, some strains produce the non-proteinaceous $\beta$-exotoxin, which shows broad-spectrum activity.

\subsection{A 41.9-kDa Protein}

Several strains of $\mathrm{Bt}$ and $\mathrm{Bc}$ encode a protein of approximately 42-kDa that has been called the 41.9-kDa protein (e.g., the Bc protein, accession number WP_000727409). These putative 41.9-kDa insecticidal toxins show some similarity to BinA and BinB, respectively, the two components of the Bin (binary toxin) from Ls. Their sequences revealed two conserved domains, a ricin B-like lectin (InterPro family IPR000772) and a Bacillus Toxin_10 crystal toxin conserved domain (InterPro family IPR008872), commonly found in other Ls and Bt toxins. To date, only one homolog protein isolated from $\mathrm{Bt}$ has been tested against a limited range of insects and was found to be non-toxic to a number of lepidopteran species and the green peach aphid Myzus persicae (Hemiptera) [94]. This may indicate that the protein has another target, that it requires another protein for its activity acting as a binary toxin or that it is not, in fact, a toxin.

\subsection{Sphaericolysins and Alveolysins}

Proteins related to cholesterol-dependent cytolysins, such as sphaericolysin from Ls and alveolysins are present in some Bt strains (e.g., sequence accession number ZP_04117355 from B. thuringiensis subsp. kurstaki) [16]. On injection, a member of this family, sphaericolysin from Ls, has activities against the cockroach Blattella germanica and the lepidopteran Spodoptera litura [95]. The very high level of sequence conservation in this family [96] makes it likely that the homologs from Bt strains will also show toxic activity.

\subsection{Beta Exotoxins}

Some Bt strains are capable of producing non-proteinaceous, thermostable and secretable secondary metabolites exhibiting non-specific toxic activity not only against a wide range of insects but also against mammals [97,98]. These secondary metabolites, commonly known as $\beta$-exotoxins (e.g., thuringiensin), are low molecular weight (700-Da) analogues of the nucleotide adenine. The production of a related beta-exotoxin type II by some strains has also been reported and this may be the uracil analog of thuringiensin [99]. Beta exotoxins cause their toxic effect by inhibition of 
DNA-dependent RNA polymerase [100], probably the reason why they may also affect mammals [101]. Beta exotoxin production is more prevalent in some serovars than others [102] and the absence of $\beta$-exotoxins is a requirement for $\mathrm{Bt}$ formulations in Europe, the US and Canada [103].

\subsection{Enhancin-Like Proteins}

Enhancin-like proteins exhibit 20\%-30\% pairwise similarity to viral enhancin proteins (metalloproteases), which favour viral infections by degrading the mucin of the protective peritrophic matrix. One of these, commonly known as Bel enhancin, has been reported to be effective in enhancing the toxicity of Cry1Ac against Helicoverpa armigera [104], whereas an identical enhancin-like protein, sharing $100 \%$ of pairwise identity with Bel enhancin, showed no significant increase in toxicity against S. exigua and Trichoplusia $n i$ when combined with Cry9Ea toxin [105].

\subsection{P19 and P20 Helper Proteins}

Crystal proteins accumulate in the cells as parasporal inclusions and can account for up to $25 \%$ of the sporulated cell dry weight [106]. Many of the Cry proteins, for example the 125- to 140-kDa protoxin forms of three-domain toxins, are capable of directing their own crystallization. However, other three-domain toxins that lack the extended $C$-terminal region in their protoxins (e.g., Cry11Aa), may require the collaboration of at least one of two accessory helper proteins (P19 and P20) $[67,106,107]$ for the stable production of parasporal crystals. These helper proteins may also have a more complex role, because P20 enhances the expression and crystallization of Cry1Ac in plasmid-negative (acrystalliferous) Bt strains [108] and synergizes the toxic activity of Cry11A against third-instar larvae of A. aegypti [109]. P20 also appears to have a role in stabilizing Cyt1 Aa [106] and increases Cyt production in $\mathrm{Bt}[68,110,111]$ and circumvents problems with Cyt expression in E. coli [112].

\section{Mechanisms of Toxin Evolution}

Bt thus synthesizes a vast number of protein toxins with activity against a wide range of organisms in nature, including not only a broad range of insect orders but also nematodes, a human-pathogenic protozoan, animal and human parasites plus different human-cancer cell lines [5,9,11,26,30,113]. Recently, a Bt strain exhibiting molluscicidal activity against the snail pest Cernuella virgata has been reported, although the molecule causing toxicity remains unknown [114]. The reasons driving such wide toxin diversification are not well understood. Perhaps, some of the most important factors are three physiological conditions that vary greatly among insects: the gut $\mathrm{pH}$, midgut proteases and toxin receptors $[21,25]$. Such factors probably exert selective pressure in toxin coding genes, forcing their evolution to adapt and overcome current and novel host defenses. For example, most of the active toxins against lepidopterans must be solubilized in the alkaline midgut and activated by proteolytic digestion of serine proteases, absent from the acidic coleopteran and hemipteran midguts. In turn, these insect guts possess mainly cysteine and aspartic proteases [21,25,115]. Interaction of insecticidal toxins with specific receptors on the gut epithelium is also a key factor in toxin evolution. For instance, resistance events against the most used Cry toxins are frequently attributed to alterations in toxin-receptor interactions [21,116]. Finally, the genomic sequence itself and the organization of 
toxin-coding genes in the genome may also contribute to toxin evolution. Most Bt strains bear large plasmids containing their toxin-coding gene repertoires [21,67,106,117,118]. The current opinion is that these plasmids are not self-mobilizable since there is not still enough evidence on their transfer mechanism except for a transfer-mediated conjugation system, reported for the Bt pX016 plasmid that may be able to mobilize toxin-coding plasmids between Bt strains [21,119] and from Bt to Ls [120]. Transfer of plasmids in infected insect larvae has also been shown in e.g., the lepidopterans Galleria mellonella and Spodoptera littoralis [121] in the soil, in other larvae and on leaf surfaces [122-124]. Transconjugant strains combining plasmids have been produced and commercialized (Foil for use against Lepidoptera and Coleoptera and Condor for use against spruce budworm and gypsy moth: produced by Ecogen Inc., Langhorne, PA, USA) and indicate that the plasmids from different strains can be compatible. The movement of plasmids in nature, may account for the discovery of cry toxin genes, related to those of Bt, in Ls [62], Paenibacillus popilliae (e.g., [125]), Paenibacillus lentimorbus [126] and Clostridium bifermentans serovar. malaysia [127] as well as the presence of cyt-like genes in Erwinia [128] and Dickeya dadantii [129]. The latter bacterium is a pathogen both of plants and of the pea aphid Acyrthosiphon pisum and it appears that induction of $c y t$ expression under conditions similar to those in phloem may be a factor in the aphid pathogenicity of the bacterium. In addition, the mobilization of plasmids between Bt strains might explain why they contain exact copies of a given Cry protein-coding gene and are distributed among geographically distinct Bt strains, for instance, the Bt strain Na205-3 (isolated from Navarra, Spain) [130] shares some, but not all, plasmids containing Bt toxin genes with Bt strain IS5056 (isolated from Biebrza, Poland) [131]. This phenomenon has also been observed among holotype vip3 gene variants (e.g., vip3C) [82] and may explain the isolation of other identical or nearly identical Vip3 protein-coding genes in more than 50 strains isolated worldwide [8]. Both cry and vip genes (and probably the cyt genes) are subjected to adaptive evolutionary forces that drive their evolution and specificity $[82,132,133]$. Phylogenetic studies suggest that genes encoding three-domain Cry proteins evolved from a common ancestor and that their diversity may have be enhanced by sequence divergence and homologous recombination [21]. Recombination of related but distinct toxin sequences seems to be a significant process in toxin evolution. Within the family of so-called three-domain Cry toxins, there are significant regions of identity [17], particularly in five conserved sequence blocks in the region of the active toxin [1] and throughout the $C$-terminal region of the large $(125-140-\mathrm{kDa})$ protoxins [134], it is postulated that this may facilitate recombination between toxin genes. The occurrence of such rearrangements is indicated by the apparently different rates of evolution for each of the three domains [38] with the pore-forming domain I evolving most slowly and domain II, which has a role in receptor binding, evolving most quickly. Rearrangement and domain shuffling of this type has been suggested as a source of dual activity (lepidopteran/coleopteran active) for toxins [135]. Further evolution of the toxins by the selection of natural mutants is likely to follow large-scale rearrangements and key residues in Cry toxin domains II and III appear to be under particular adaptive pressure [132] as does the $C$-terminus of the Vip3 protein [133]. It is interesting to note that phylogenetic trees based on the three domains, produce different families of toxins from those using full protoxin sequences $[17,38,135]$. It is possible that the location of toxin genes on plasmids may allow a higher rate of recombination due to the greater proximity of individual genes (relative to genes scattered around the main genome). Recombination events during toxin evolution may also be the 
source of sequences on the toxin-coding plasmid pBtoxis, of Bt serovar. israelensis that appear to be remnant fragments of toxin genes [67]. Gonzales and Carlton demonstrated the potential of this plasmid to rearrange and recombine with other plasmids in different ways, when subjected to growth at an elevated temperature of $42{ }^{\circ} \mathrm{C}$. For instance, recombination of pBtoxis (which they referred to as the 75-MDa plasmid) was observed with a 68-MDa ( 110 kb) plasmid to create new $63-\mathrm{MDa}(\sim 105 \mathrm{~kb})$ and $80-\mathrm{MDa}(\sim 135 \mathrm{~kb})$ plasmids [136]. The apparent absence of cry4Aa and cryl0Aa genes from the toxin coding plasmid related to pBtoxis in the Tunisian isolate BUPM97 of Bt serovar. israelensis [137] may be explained by such rearrangements or could represent a plasmid that had never acquired these genes while plasmid pBTHD789-3 from Bt israelensis strain HD789 is also similar to pBtoxis but carries an additional Cry4B gene and two Cry60 genes [138]. Finally, many toxin-coding genes have been found flanked by sequences coding for putative transposons and transposases $[21,67]$. This may indicate that these genes can be acquired independently and represent a further source of toxin evolution. The vestigial toxin gene remnants of the pBtoxis plasmid, especially those containing nearby transposons sequences, may represent evidence of recombination or transposition events [21,67]. Gene duplication is evident in Ls where two identical copies of the genes encoding the mosquitocidal Bin toxin are encoded; one copy in the genome and one copy on the large pBsph plasmid $[139,140]$. Gene duplication, followed by sequence divergence, may also lead to small-scale diversification of toxins active against the same target. Different members of the same Cry toxin family in individual isolates (e.g., Cry1Aa, Cry1Ab \& Cry1Ac and Cry2Aa and Cry2Ab in Bt serovar. kurstaki HD1 [141] may be a result of such events and the presence in strains of multiple toxins from a single first-level Cry family is common [141,142]. The resulting toxins may, however, share receptors $[143,144]$ and in some instances, may interact antagonistically [145,146].

\section{Novel Toxins and Next-Generation Sequencing (NGS) Technologies}

Since the first $B$. thuringiensis insecticidal genes were discovered, the search for other genes encoding novel proteins with promising insecticidal properties and specificities has continued. Such screenings were carried out mainly with polymerase chain reaction (PCR) or a combination of PCR and restriction fragment length polymorphism (PCR-RFLP) approaches [147-152]. However, these PCR-based techniques are slow, laborious and limited, because they mainly identified alleles of previously described genes; these new genes usually displayed just a small number of synonymous or non-synonymous substitutions, and encoded identical or slightly different proteins compared to previously described alleles, likely having very similar toxicity and host range. In addition, since these techniques yield only a fraction of the gene sequence, time-consuming PCR walking strategies or construction of genomic libraries and screening are needed to obtain a single full-length coding sequence suitable for cloning.

Finding novel proteins is particularly important to manage the increasing occurrence of resistance to Bt-based insecticides or transgenic Bt plants [116,153,154]. Today, next-generation sequencing (NGS) technologies [155-159] are available as novel and useful tools for the discovery of previously unrecognized insecticidal-toxin genes that would otherwise be difficult to identify. NGS technologies provide a fast and reliable framework to obtain complete genomic sequences, and offer excellent cost-benefit ratios since complete genome sequences can be obtained for less than 0.1-1 euro per 
kilobase. This cost may be reduced even further if only raw sequence production is outsourced and the researcher completes the assembly steps. Sequences can readily be assembled in contigs using a regular desktop computer [160] with de novo assembly tools bundled in bioinformatic software, such as CLC Genomics Workbench or Geneious Pro (both commercial software), or using diverse open source assemblers freely available in the BioLinux distribution [161], among other alternatives [162]. Insecticidal gene prediction and annotation could be easily accomplished using the NCBI Blast tools [163], using customized (insecticidal) BLAST databases [94,130,164] or the BtToxin_Scanner [165]. Once the full-length toxin-coding sequence (or sequences) is identified, it can be easily amplified by PCR and cloned for protein expression, in the host system of choice.

While mass sequencing programs offer huge potential for the discovery of new toxin sequences, the number and diversity of toxins discovered will present real challenges to the toxin nomenclature system that has served the Bt community well for many years. Such challenges include the sheer numbers of new variant toxins that may overwhelm the system as well as nomenclature difficulties within the present system. For example, the current nomenclature may contain two proteins with different secondary ranks (e.g., Cry5A and Cry5E) when a new variant sharing $>78 \%$ identity with both is discovered. Placing such new variants in the nomenclature will present difficulties as more toxins emerge and solutions to this issue will be needed.

\section{Concluding Remarks}

Bacillus thuringiensis (Bt) is a Gram-positive, spore-forming bacterium that synthesizes an extraordinary diversity of insecticidal proteins and has demonstrated its potential and safety as a biocontrol agent over more than five decades. There is now an extensive literature on a wide range of Bt-related topics from its natural ecology to its mode of action. A large number of toxins, active against a wide range of invertebrates have been described along with a number of proteins with activities against cancer cells in culture. The evolution and diversification of these toxins is likely to be driven by an arms race between pathogen and target and to be facilitated by recombination events between related genes, transposition and plasmid transfer. The insecticidal proteins include both crystal and secreted proteins highly toxic against a wide range of invertebrate species $[5,6,18,26]$ and our understanding of their modes of action and structural biology are increasing, as described in this review. Several natural Bt strains have been incorporated successfully in the production of sprayable Bt-based bioinsecticides wherein the active ingredient is a mixture of spores and protein crystals.

The wide diversity of insecticidal proteins produced by this bacterium suggest that their encoding genes are affected by strong selective evolutionary pressures $[18,105,106]$ leading to the expansion of the range of targets and turning $\mathrm{Bt}$ into a rich source of proteins with toxic activities against insects and other organisms. The innovations of NGS technologies are likely to increase our arsenal of toxins still further and with increased efficiency. This expansion in toxin discovery is also likely to put the toxin nomenclature system under increasing pressure and this may require novel strategies to keep pace with the new technology. 


\section{Acknowledgments}

This research was supported by the Spanish Ministry of Science and Innovation (grant reference AGL2009-13340-C02) and by the Universidad Pública de Navarra (PhD contract awarded to Leopoldo Palma).

\section{Authors Contribution}

Leopoldo Palma, Delia Muñoz and Primitivo Caballero conceived and designed the review idea and contents. Leopoldo Palma, Colin Berry, Jesús Murillo and Primitivo Caballero contributed writing and revising the paper.

\section{Abbreviations}

Bc, Bacillus cereus; Bt, Bacillus thuringiensis; Ls, Lysinibacillus sphaericus.

\section{Conflicts of Interest}

The authors declare no conflict of interest.

\section{References}

1. Höfte, H.; Whiteley, H.R. Insecticidal Crystal Proteins of Bacillus thuringiensis. Microbiol. Rev. 1989, 53, 242-255.

2. Knowles, B.H.; Dow, J.A.T. The crystal delta-endotoxins of Bacillus thuringiensis-Models for their mechanism of action on the insect gut. Bioessays 1993, 15, 469-476.

3. Raymond, B.; Johnston, P.R.; Nielsen-LeRoux, C.; Lereclus, D.; Crickmore, N. Bacillus thuringiensis: An impotent pathogen? Trends Microbiol. 2010, 18, 189-194.

4. Roh, J.Y.; Choi, J.Y.; Li, M.S.; Jin, B.R.; Je, Y.H. Bacillus thuringiensis as a specific, safe, and effective tool for insect pest control. J. Mol. Biol. 2007, 17, 547-559.

5. Schnepf, E.; Crickmore, N.; van Rie, J.; Lereclus, D.; Baum, J.; Feitelson, J.; Zeigler, D.R.; Dean, D.H. Bacillus thuringiensis and its pesticidal crystal proteins. Microbiol. Mol. Biol. Rev. 1998, 62, 775-806.

6. Sanchis, V. From microbial sprays to insect-resistant transgenic plants: History of the biospesticide Bacillus thuringiensis. A review. Agron. Sustain. Dev. 2011, 31, 217-231.

7. Bravo, A.; Gill, S.S.; Soberón, M. Mode of action of Bacillus thuringiensis Cry and Cyt toxins and their potential for insect control. Toxicon 2007, 49, 423-435.

8. Crickmore, N.; Zeigler, D.R.; Schnepf, E.; van Rie, J.; Lereclus, D.; Baum, J.; Bravo, A.; Dean, D.H. Bacillus thuringiensis Toxin Nomenclature. Available online: http://www.lifesci. sussex.ac.uk/Home/Neil_Crickmore/Bt/ (accessed on 7 November 2014).

9. Van Frankenhuyzen, K. Insecticidal activity of Bacillus thuringiensis crystal proteins. J. Invertebr. Pathol. 2009, 101, 1-16.

10. Sanchis, V.; Bourguet, D. Bacillus thuringiensis: Applications in agriculture and insect resistance management. A review. Agron. Sustain. Dev. 2008, 28, 11-20. 
11. Ohba, M.; Mizuki, E.; Uemori, A. Parasporin, a new anticancer protein group from Bacillus thuringiensis. Anticancer Res. 2009, 29, 427-433.

12. Okumura, S.; Ohba, M.; Mizuki, E.; Crickmore, N.; Coté, J.-C.; Nagamatsu, Y.; Kitada, S.; Sakai, H.; Harata, K.; Shin, T.; et al. Parasporin Nomenclature. Available online: http://parasporin.fitc.pref.fukuoka.jp/ (accessed on 7 November 2014).

13. Estruch, J.J.; Warren, G.W.; Mullins, M.A.; Nye, G.J.; Craig, J.A.; Koziel, M.G. Vip3A, a novel Bacillus thuringiensis vegetative insecticidal protein with a wide spectrum of activities against lepidopteran insects. Proc. Natl. Acad. Sci. USA 1996, 93, 5389-5394.

14. Warren, G.W.; Koziel, M.G.; Mullins, M.A.; Nye, G.J.; Carr, B.; Desai, N.M.; Kostichka, K.; Duck, N.B.; Estruch, J.J. Auxiliary Proteins for Enhancing the Insecticidal Activity of Pesticidal Proteins. U.S. Patent 5,770,696, 23 June 1998.

15. Donovan, W.P.; Engleman, J.T.; Donovan, J.C.; Baum, J.A.; Bunkers, G.J.; Chi, D.J.; Clinton, W.P.; English, L.; Heck, G.R.; Ilagan, O.M.; et al. Discovery and characterization of Sip1A: A novel secreted protein from Bacillus thuringiensis with activity against coleopteran larvae. Appl. Microbiol. Biotechnol. 2006, 72, 713-719.

16. Schnepf, H.E.; Whiteley, H.R. Cloning and expression of the Bacillus thuringiensis crystal protein gene in Escherichia coli. Proc. Natl. Acad. Sci. USA 1981, 78, 2893-2897.

17. Crickmore, N.; Zeigler, D.R.; Feitelson, J.; Schnepf, E.; van Rie, J.; Lereclus, D.; Baum, J.; Dean, D.H. Revision of the nomenclature for the Bacillus thuringiensis pesticidal crystal proteins. Microbiol. Mol. Biol. Rev. 1998, 62, 807-813.

18. Ben-Dov, E. Bacillus thuringiensis subsp. israelensis and Its Dipteran-Specific Toxins. Toxins 2014, 6, 1222-1243.

19. Butko, P. Cytolytic toxin Cyt1A and its mechanism of membrane damage: Data and hypotheses. Appl. Environ. Microbiol. 2003, 69, 2415-2422.

20. Cohen, S.; Albeck, S.; Ben-Dov, E.; Cahan, R.; Firer, M.; Zaritsky, A.; Dym, O. Cyt1Aa toxin: Crystal structure reveals implications for its membrane-perforating function. J. Mol. Biol. 2011, 413, 804-814.

21. De Maagd, R.A.; Bravo, A.; Berry, C.; Crickmore, N.; Schnepf, H.E. Structure, diversity, and evolution of protein toxins from spore-forming entomopathogenic bacteria. Annu. Rev. Genet. 2003, 37, 409-433.

22. Soberon, M.; Lopez-Diaz, J.A.; Bravo, A. Cyt toxins produced by Bacillus thuringiensis: A protein fold conserved in several pathogenic microorganisms. Peptides 2013, 41, 87-93.

23. Yu, X.; Liu, T.; Sun, Z.; Guan, P.; Zhu, J.; Wang, S.; Li, S.; Deng, Q.; Wang, L.; Zheng, A.; et al. Co-expression and synergism analysis of Vip3Aa29 and Cyt2Aa3 insecticidal proteins from Bacillus thuringiensis. Curr. Microbiol. 2012, 64, 326-331.

24. Berry, C. The bacterium, Lysinibacillus sphaericus, as an insect pathogen. J. Invertebr. Pathol. 2012, 109, 1-10.

25. Chougule, N.P.; Bonning, B.C. Toxins for transgenic resistance to hemipteran pests. Toxins 2012, 4, 405-429.

26. Van Frankenhuyzen, K. Cross-order and cross-phylum activity of Bacillus thuringiensis pesticidal proteins. J. Invertebr. Pathol. 2013, 114, 76-85. 
27. Ali, B.A.; Salem, H.H.; Wang, X.M.; Huang, T.H.; Xie, Q.D.; Zhang, X.Y. Effect of Bacillus thuringiensis var. israelensis endotoxin on the intermediate snail host of Schistosoma japonicum. Curr. Res. Bacteriol. 2010, 3, 37-41.

28. Bravo, A.; Soberón, M. How to cope with insect resistance to Bt toxins? Trends Biotechnol. 2008, 26, 573-579.

29. Mizushiro, H.; Akao, T.; Yamashita, S.; Oba, M.; Kondo, S.; Maeda, M. Protien Having Antitrichomonal Activity and Derived from Bacillus thuringiensis and Method for Preparing the Same. Japanese Patent JP2002284800, 3 October 2002.

30. Kondo, S.; Mizuki, E.; Akao, T.; Ohba, M. Antitrichomonal strains of Bacillus thuringiensis. Parasitol. Res. 2002, 88, 1090-1092.

31. Halima, H.S.; Bahy, A.A.; Tian, H.H.; Qing, D.X. Molecular characterization of novel Bacillus thuringiensis isolate with molluscicidal activity against the intermediate host of schistosomes. Biotechnology 2006, 5, 413-420.

32. Ross, A.G.P.; Sleigh, A.C.; Li, Y.S.; Davis, G.M.; Williams, G.M.; Jiang, Z.; Feng, Z.; McManus, D.P. Schistosomiasis in the People's Republic of China: Prospects and challenges for the 21st century. Clin. Microbiol. Rev. 2001, 14, 270-295.

33. Naimov, S.; Boncheva, R.; Karlova, R.; Dukiandjiev, S.; Minkov, I.; de Maagd, R.A. Solubilization, activation, and insecticidal activity of Bacillus thuringiensis serovar thompsoni HD542 crystal proteins. Appl. Environ. Microbiol. 2008, 74, 7145-7151.

34. Wei, J.Z.; Hale, K.; Carta, L.; Platzer, E.; Wong, C.; Fang, S.C.; Aroian, R.V. Bacillus thuringiensis crystal proteins that target nematodes. Proc. Natl. Acad. Sci. USA 2003, 100, 2760-2765.

35. Yudina, T.G.; Brioukhanov, A.L.; Zalunin, I.A.; Revina, L.P.; Shestakov, A.I.; Voyushina, N.E.; Chestukhina, G.G.; Netrusov, A.I. Antimicrobial activity of different proteins and their fragments from Bacillus thuringiensis parasporal crystals against clostridia and archaea. Anaerobe 2007, 13, 6-13.

36. Revina, L.P.; Kostina, L.I.; Dronina, M.A.; Zalunin, I.A.; Chestukhina, G.G.; Yudina, T.G.; Konukhova, A.V.; Izumrudova, A.V. Novel antibacterial proteins from entomocidal crystals of Bacillus thuringiensis ssp israelensis. Can. J. Microbiol. 2005, 51, 141-148.

37. Yudina, T.G.; Konukhova, A.V.; Revina, L.P.; Kostina, L.I.; Zalunin, I.A.; Chestukhina, G.G. Antibacterial activity of Cry- and Cyt-proteins from Bacillus thuringiensis ssp israelensis. Can. J. Microbiol. 2003, 49, 37-44.

38. De Maagd, R.A.; Bravo, A.; Crickmore, N. How Bacillus thuringiensis has evolved specific toxins to colonize the insect world. Trends Genet. 2001, 17, 193-199.

39. Pardo-López, L.; Soberón, M.; Bravo, A. Bacillus thuringiensis insecticidal three-domain Cry toxins: Mode of action, insect resistance and consequences for crop protection. FEMS Microbiol. Rev. 2013, 37, 3-22.

40. Morse, R.J.; Yamamoto, T.; Stroud, R.M. Structure of Cry2Aa suggests an unexpected receptor binding epitope. Structure 2001, 9, 409-417.

41. Xu, C.; Wang, B.C.; Yu, Z.; Sun, M. Structural insights into Bacillus thuringiensis Cry, Cyt and parasporin toxins. Toxins 2014, 6, 2732-2770. 
42. Jenkins, J.L.; Dean, D.H. Exploring the mechanism of action of insecticidal proteins by genetic engineering methods. Genet. Eng. (N.Y.) 2000, 22, 33-54.

43. Evdokimov, A.G.; Moshiri, F.; Sturman, E.J.; Rydel, T.J.; Zheng, M.; Seale, J.W.; Franklin, S. Structure of the full-length insecticidal protein Cry1Ac reveals intriguing details of toxin packaging into in vivo formed crystals. Protein Sci. 2014, 23, 1491-1497.

44. Du, C.; Martin, P.A.; Nickerson, K.W. Comparison of Disulfide Contents and Solubility at Alkaline $\mathrm{pH}$ of Insecticidal and Noninsecticidal Bacillus thuringiensis Protein Crystals. Appl. Environ. Microbiol. 1994, 60, 3847-3853.

45. Creighton, T.E. Disulfide bonds as probes of protein folding pathways. Meth. Enzymol. 1986, 131, 83-106.

46. Vachon, V.; Laprade, R.; Schwartz, J.L. Current models of the mode of action of Bacillus thuringiensis insecticidal crystal proteins: A critical review. J. Invertebr. Pathol. 2012, $111,1-12$.

47. Kirouac, M.; Vachon, V.; Noel, J.F.; Girard, F.; Schwartz, J.L.; Laprade, R. Amino acid and divalent ion permeability of the pores formed by the Bacillus thuringiensis toxins Cry1Aa and Cry1Ac in insect midgut brush border membrane vesicles. Bba-Biomembranes 2002, 1561, 171-179.

48. Zhang, X.B.; Candas, M.; Griko, N.B.; Taussig, R.; Bulla, L.A. A mechanism of cell death involving an adenylyl cyclase/PKA signaling pathway is induced by the Cry $1 \mathrm{Ab}$ toxin of Bacillus thuringiensis. Proc. Natl. Acad. Sci. USA 2006, 103, 9897-9902.

49. Pigott, C.R.; Ellar, D.J. Role of receptors in Bacillus thuringiensis crystal toxin activity. Microbiol. Mol. Biol. Rev. 2007, 71, 255-281.

50. Fernandez-Luna, M.T.; Lanz-Mendoza, H.; Gill, S.S.; Bravo, A.; Soberon, M.; Miranda-Rios, J. An alpha-amylase is a novel receptor for Bacillus thuringiensis ssp. israelensis Cry4Ba and Cry11Aa toxins in the malaria vector mosquito Anopheles albimanus (Diptera: Culicidae). Environ. Microbiol. 2010, 12, 746-757.

51. Zhang, Q.; Hua, G.; Bayyareddy, K.; Adang, M.J. Analyses of alpha-amylase and alpha-glucosidase in the malaria vector mosquito, Anopheles gambiae, as receptors of Cry $11 \mathrm{Ba}$ toxin of Bacillus thuringiensis subsp. jegathesan. Insect Biochem. Mol. Biol. 2013, 43, 907-915.

52. Kuadkitkan, A.; Smith, D.R.; Berry, C. Investigation of the Cry4B-prohibitin interaction in Aedes aegypti cells. Curr. Microbiol. 2012, 65, 446-454.

53. Likitvivatanavong, S.; Chen, J.; Evans, A.M.; Bravo, A.; Soberon, M.; Gill, S.S. Multiple receptors as targets of Cry toxins in mosquitoes. J. Agric. Food Chem. 2011, 59, 2829-2838.

54. Zhang, R.; Hua, G.; Andacht, T.M.; Adang, M.J. A 106-kDa aminopeptidase is a putative receptor for Bacillus thuringiensis Cry11Ba toxin in the mosquito Anopheles gambiae. Biochemistry 2008, 47, 11263-11272.

55. Gonzalez, M.R.; Bischofberger, M.; Pernot, L.; van der Goot, F.G.; Freche, B. Bacterial pore-forming toxins: The (w)hole story? Cell. Mol. Life Sci. 2008, 65, 493-507.

56. Knapp, O.; Stiles, B.; Popoff, M.R. The aerolysin-like toxin family of cytolytic, pore-forming toxins. Open Toxinol. J. 2010, 3, 53-68.

57. Popoff, M.R. Epsilon toxin: A fascinating pore-forming toxin. FEBS J. 2011, 278, 4602-4615. 
58. Kelker, M.S.; Berry, C.; Evans, S.L.; Pai, R.; McCaskill, D.G.; Wang, N.X.; Russell, J.C.; Baker, M.D.; Yang, C.; Pflugrath, J.W.; et al. Structural and biophysical characterization of Bacillus thuringiensis insecticidal proteins Cry34Ab1 and Cry35Ab1. PLoS One 2014, 9, e112555.

59. Srisucharitpanit, K.; Yao, M.; Promdonkoy, B.; Chimnaronk, S.; Tanaka, I.; Boonserm, P. Crystal structure of BinB: A receptor binding component of the binary toxin from Lysinibacillus sphaericus. Proteins 2014, 82, 2703-2712.

60. Akiba, T.; Abe, Y.; Kitada, S.; Kusaka, Y.; Ito, A.; Ichimatsu, T.; Katayama, H.; Akao, T.; Higuchi, K.; Mizuki, E.; et al. Crystal Structure of the Parasporin-2 Bacillus thuringiensis Toxin That Recognizes Cancer Cells. J. Mol. Biol. 2009, 386, 121-133.

61. Akiba, T.; Higuchi, K.; Mizuki, E.; Ekino, K.; Shin, T.; Ohba, M.; Kanai, R.; Harata, K. Nontoxic crystal protein from Bacillus thuringiensis demonstrates a remarkable structural similarity to beta-pore-forming toxins. Proteins 2006, 63, 243-248.

62. Jones, G.W.; Nielsen-Leroux, C.; Yang, Y.; Yuan, Z.; Dumas, V.F.; Monnerat, R.G.; Berry, C. A new Cry toxin with a unique two-component dependency from Bacillus sphaericus. FASEB J. 2007, 21, 4112-4120.

63. Hey, T.D.; Narva, K.; Woosley, A.T. Modified Bacillus thuringiensis Cry6 Proteins for Nematode Control. U.S. Patent 201,110,225,681, 15 September 2011.

64. Yu, Z.; Luo, H.; Xiong, J.; Zhou, Q.; Xia, L.; Sun, M.; Li, L.; Yu, Z. Bacillus thuringiensis Cry6A exhibits nematicidal activity to Caenorhabditis elegans bre mutants and synergistic activity with Cry5B to C. elegans. Lett. Appl. Microbiol. 2014, 58, 511-519.

65. Guerchicoff, A.; Delecluse, A.; Rubinstein, C.P. The Bacillus thuringiensis cyt genes for hemolytic endotoxins constitute a gene family. Appl. Environ. Microbiol. 2001, 67, 1090-1096.

66. Cohen, S.; Dym, O.; Albeck, S.; Ben-Dov, E.; Cahan, R.; Firer, M.; Zaritsky, A. High-resolution crystal structure of activated Cyt2Ba monomer from Bacillus thuringiensis subsp. israelensis. J. Mol. Biol. 2008, 380, 820-827.

67. Berry, C.; O’Neil, S.; Ben-Dov, E.; Jones, A.F.; Murphy, L.; Quail, M.A.; Holden, M.T.; Harris, D.; Zaritsky, A.; Parkhill, J.; et al. Complete sequence and organization of pBtoxis, the toxin-coding plasmid of Bacillus thuringiensis subsp. israelensis. Appl. Environ. Microbiol. 2002, 68, 5082-5095.

68. Manasherob, R.; Itsko, M.; Sela-Baranes, N.; Ben-Dov, E.; Berry, C.; Cohen, S.; Zaritsky, A. Cyt1Ca from Bacillus thuringiensis subsp. israelensis: Production in Escherichia coli and comparison of its biological activities with those of other Cyt-like proteins. Microbiology 2006, 152, 2651-2659.

69. Federici, B.A.; Bauer, L.S. Cyt1Aa protein of Bacillus thuringiensis is toxic to the cottonwood leaf beetle, Chrysomela scripta, and suppresses high levels of resistance to Cry3Aa. Appl. Environ. Microbiol. 1998, 64, 4368-4371.

70. Wirth, M.C.; Delecluse, A.; Walton, W.E. Cyt1Ab1 and Cyt2Ba1 from Bacillus thuringiensis subsp. medellin and B. thuringiensis subsp. israelensis synergize Bacillus sphaericus against Aedes aegypti and resistant Culex quinquefasciatus (Diptera: Culicidae). Appl. Environ. Microbiol. 2001, 67, 3280-3284.

71. Zhang, B.H.; Liu, M.; Yang, Y.K.; Yuan, Z.M. Cytolytic toxin Cyt1Aa of Bacillus thuringiensis synergizes the mosquitocidal toxin Mtx1 of Bacillus sphaericus. Biosci. Biotech. Bioch. 2006, 70, 2199-2204. 
72. Donovan, W.P.; Donovan, J.C.; Engleman, J.T. Gene knockout demonstrates that vip3A contributes to the pathogenesis of Bacillus thuringiensis toward Agrotis ipsilon and Spodoptera exigua. J. Invertebr. Pathol. 2001, 78, 45-51.

73. Milne, R.; Liu, Y.; Gauthier, D.; van Frankenhuyzen, K. Purification of Vip3Aa from Bacillus thuringiensis HD-1 and its contribution to toxicity of HD-1 to spruce budworm (Choristoneura fumiferana) and gypsy moth (Lymantria dispar) (Lepidoptera). J. Invertebr. Pathol. 2008, 99, 166-172.

74. Shi, Y.; Ma, W.; Yuan, M.; Sun, F.; Pang, Y. Cloning of vip1/vip2 genes and expression of Vip1Ca/Vip2Ac proteins in Bacillus thuringiensis. World J. Microbiol. Biotechnol. 2006, 23, 501-507.

75. Sattar, S.; Maiti, M.K. Molecular characterization of a novel vegetative insecticidal protein from Bacillus thuringiensis effective against sap-sucking insect pest. J. Microbiol. Biotechnol. 2011, 21, 937-946.

76. Gatehouse, J.A. Biotechnological prospects for engineering insect-resistant plants. Plant Physiol. 2008, 146, 881-887.

77. Barth, H.; Aktories, K.; Popoff, M.R.; Stiles, B.G. Binary bacterial toxins: Biochemistry, biology, and applications of common Clostridium and Bacillus proteins. Microbiol. Mol. Biol. Rev. 2004, 68, 373-402.

78. Han, S.; Craig, J.A.; Putnam, C.D.; Carozzi, N.B.; Tainer, J.A. Evolution and mechanism from structures of an ADP-ribosylating toxin and NAD complex. Nat. Struct. Biol. 1999, 6, 932-936.

79. Shi, Y.; Xu, W.; Yuan, M.; Tang, M.; Chen, J.; Pang, Y. Expression of vip1/vip2 genes in Escherichia coli and Bacillus thuringiensis and the analysis of their signal peptides. J. Appl. Microbiol. 2004, 97, 757-765.

80. MacIntosh, S.C.; Stone, T.B.; Sims, S.R.; Hunst, P.L.; Greenplate, J.T.; Marrone, P.G.; Perlak, F.J.; Fischhoff, D.A.; Fuchs, R.L. Specificity and efficacy of purified Bacillus thuringiensis proteins against agronomically important insects. J. Invertebr. Pathol. 1990, 56, 258-266.

81. Rang, C.; Gil, P.; Neisner, N.; van Rie, J.; Frutos, R. Novel Vip3-related protein from Bacillus thuringiensis. Appl. Environ. Microbiol. 2005, 71, 6276-6281.

82. Palma, L.; Hernández-Rodríguez, C.S.; Maeztu, M.; Hernández-Martínez, P.; Ruiz de Escudero, I.; Escriche, B.; Muñoz, D.; van Rie, J.; Ferré, J.; Caballero, P.; et al. Vip3C, a novel class of vegetative insecticidal proteins from Bacillus thuringiensis. Appl. Environ. Microbiol. 2012, 78, 7163-7165.

83. Li, C.; Xu, N.; Huang, X.; Wang, W.; Cheng, J.; Wu, K.; Shen, Z. Bacillus thuringiensis Vip3 mutant proteins: Insecticidal activity and trypsin sensitivity. Biocontrol Sci. Technol. 2007, 17, 699-708.

84. Estruch, J.J.; Yu, C.G. Plant Pest Control. Patent WO 9,844,137, 17 December 1998.

85. Bommireddy, P.L.; Leonard, B.R.; Emfinger, K. Heliothine larval behavior on transgenic cotton expressing a Bacillus thuringiensis insecticidal exotoxin, Vip3A. J. Cotton Sci. 2007, 11, 199-207.

86. Palma, L.; Berry, C.; Caballero, P. Universidad Pública de Navarra (Spain and Cardiff University) (United Kingdom), Pamplona, Spain. Unpublished Work, 2014. 
87. Lee, M.K.; Walters, F.S.; Hart, H.; Palekar, N.; Chen, J.S. The mode of action of the Bacillus thuringiensis vegetative insecticidal protein Vip3A differs from that of Cry $1 \mathrm{Ab}$ delta-endotoxin. Appl. Environ. Microbiol. 2003, 69, 4648-4657.

88. Yu, C.G.; Mullins, M.A.; Warren, G.W.; Koziel, M.G.; Estruch, J.J. The Bacillus thuringiensis vegetative insecticidal protein Vip3A lyses midgut epithelium cells of susceptible insects. Appl. Environ. Microbiol. 1997, 63, 532-536.

89. Sena, J.A.D.; Hernández-Rodríguez, C.S.; Ferré, J. Interaction of Bacillus thuringiensis Cry1 and Vip3A proteins with Spodoptera frugiperda midgut binding sites. Appl. Environ. Microbiol. 2009, 75, 2236-2237.

90. Lee, M.K.; Miles, P.; Chen, J.-S. Brush border membrane binding properties of Bacillus thuringiensis Vip3A toxin to Heliothis virescens and Helicoverpa zea midguts. Biochem. Biophys. Res. Commun. 2006, 339, 1043-1047.

91. Mike, C.; Ryan, J.; Maria, M.; Martin, T.; Dickerson, D.; Negrotto, D.; O’Reilly, D.; Chen, E.; Lee, M. Effective IRM with a novel insecticidal protein, Vip3A. In Proceedings of the Beltwide Cotton Conference, San Antonio, TX, USA, 3-6 January 2006; National Cotton Council: Memphis, TN, USA, 2006; pp. 1229-1235.

92. Bravo, A.; Likitvivatanavong, S.; Gill, S.S.; Soberón, M. Bacillus thuringiensis: A story of a successful bioinsecticide. Insect Biochem. Mol. Biol. 2011, 41, 423-431.

93. Mehlo, L.; Gahakwa, D.; Nghia, P.T.; Loc, N.T.; Capell, T.; Gatehouse, J.A.; Gatehouse, A.M.; Christou, P. An alternative strategy for sustainable pest resistance in genetically enhanced crops. Proc. Natl. Acad. Sci. USA 2005, 102, 7812-7816.

94. Palma, L.; Muñoz, D.; Berry, C.; Murillo, J.; Caballero, P. Draft genome sequences of two Bacillus thuringiensis strains and characterization of a putative $41.9-\mathrm{kDa}$ insecticidal toxin. Toxins 2014, 6, 1490-1504.

95. Nishiwaki, H.; Nakashima, K.; Ishida, C.; Kawamura, T.; Matsuda, K. Cloning, functional characterization, and mode of action of a novel insecticidal pore-forming toxin, sphaericolysin, produced by Bacillus sphaericus. Appl. Environ. Microbiol. 2007, 73, 3404-3411.

96. Silva-Filha, M.H.N.L.; Berry, C.; Regis, L. Lysinibacillus sphaericus: Toxins and mode of action, applications for mosquito control and resistance management. In Advances in Insect Physiology: Insect Midgut and Insecticidal Proteins; Dhadialla, T.S., Gill, S.S., Eds.; Elsevier: Oxford, UK, 2014; Volume 47, pp. 89-176.

97. Liu, X.Y.; Ruan, L.F.; Hu, Z.F.; Peng, D.H.; Cao, S.Y.; Yu, Z.N.; Liu, Y.; Zheng, J.S.; Sun, M. Genome-wide screening reveals the genetic determinants of an antibiotic insecticide in Bacillus thuringiensis. J. Biol. Chem. 2010, 285, 39191-39200.

98. Liu, X.; Ruan, L.; Peng, D.; Li, L.; Sun, M.; Yu, Z. Thuringiensin: A Thermostable Secondary Metabolite from Bacillus thuringiensis with Insecticidal Activity against a Wide Range of Insects. Toxins 2014, 6, 2229-2238.

99. Levinson, B.L.; Kasyan, K.J.; Chiu, S.S.; Currier, T.C.; Gonzalez, J.M., Jr. Identification of beta-exotoxin production, plasmids encoding beta-exotoxin, and a new exotoxin in Bacillus thuringiensis by using high-performance liquid chromatography. J. Bacteriol. 1990, 172, 3172-3179. 
100. Gohar, M.; Perchat, S. Sample preparation for beta-exotoxin determination in Bacillus thuringiensis cultures by reversed-phase high-performance liquid chromatography. Anal. Biochem. 2001, 298, 112-117.

101. McClintock, J.; Stone, T.B.; Sjoblad, R.D. A comparative review of the mammalian toxicity of Bacillus thuringiensis-based pesticides. Pest Manag. Sci. 1995, 45, 95-105.

102. Hernandez, C.S.; Martinez, C.; Porcar, M.; Caballero, P.; Ferre, J. Correlation between serovars of Bacillus thuringiensis and type I beta-exotoxin production. J. Invertebr. Pathol. 2003, 82, 57-62.

103. Glare, T.R.; O’Callaghan, M. Bacillus Thuringiensis: Biology, Ecology and Safety; Wiley: Chichester, UK, 2000.

104. Fang, S.L.; Wang, L.; Guo, W.; Zhang, X.; Peng, D.H.; Luo, C.P.; Yu, Z.I.; Sun, M. Bacillus thuringiensis Bel protein enhances the toxicity of Cry1Ac protein to Helicoverpa armigera larvae by degrading insect intestinal mucin. Appl. Environ. Microbiol. 2009, 75, 5237-5243.

105. Zhao, D.; Guo, W.; Sun, W.; Xu, D.; Liu, D. Identification of a novel enhancin-like gene from Bacillus thuringiensis. Front. Agric. China 2011, 5, 423-429.

106. Agaisse, H.; Lereclus, D. How does Bacillus thuringiensis produce so much insecticidal crystal protein? J. Bacteriol. 1995, 177, 6027-6032.

107. Ibrahim, M.A.; Griko, N.; Junker, M.; Bulla, L.A. Bacillus thuringiensis: A genomics and proteomics perspective. Bioeng. Bugs 2010, 1, 31-50.

108. Shao, Z.; Liu, Z.; Yu, Z. Effects of the 20-kilodalton helper protein on Cry1Ac production and spore formation in Bacillus thuringiensis. Appl. Environ. Microbiol. 2001, 67, 5362-5369.

109. Xu, Y.; Nagai, M.; Bagdasarian, M.; Smith, T.W.; Walker, E.D. Expression of the 220 gene from Bacillus thuringiensis H-14 increases Cry11A toxin production and enhances mosquito-larvicidal activity in recombinant gram-negative bacteria. Appl. Environ. Microbiol. 2001, 67, 3010-3015.

110. Wu, D.; Federici, B.A. A 20-kilodalton protein preserves cell viability and promotes CytA crystal formation during sporulation in Bacillus thuringiensis. J. Bacteriol. 1993, 175, 5276-5280.

111. Nisnevitch, M.; Cohen, S.; Ben-Dov, E.; Zaritsky, A.; Sofer, Y.; Cahan, R. Cyt2Ba of Bacillus thuringiensis israelensis: Activation by putative endogenous protease. Biochem. Biophys. Res. Commun. 2006, 344, 99-105.

112. Douek, J.; Einav, M.; Zaritsky, A. Sensitivity to plating of Escherichia coli cells expressing the cryA gene from Bacillus thuringiensis var. israelensis. Mol. Gen. Genet. 1992, 232, 162-165.

113. Peña, G.; Aguilar Jiménez, F.A.; Hallal-Calleros, C.; Morales-Montor, J.; Hernández-Velázquez, V.M.; Flores-Pérez, F.I. In vitro ovicidal and cestocidal efects of toxins from Bacillus thuringiensis on the canine and human parasite Dipylidium caninum. BioMed Res. Int. 2013, 2013, 174619. doi:10.1155/2013/174619.

114. Wang, A.; Pattemore, J.; Ash, G.; Williams, A.; Hane, J. Draft genome sequence of Bacillus thuringiensis strain DAR 81934, which exhibits molluscicidal activity. J. Bacteriol. 2013, 1 , e00175-12. 
115. Wright, M.K.; Brandt, S.L.; Coudron, T.A.; Wagner, R.M.; Habibi, J.; Backus, E.A.; Huesing, J.E. Characterization of digestive proteolytic activity in Lygus hesperus Knight (Hemiptera: Miridae). J. Insect Physiol. 2006, 52, 717-728.

116. Ferré, J.; van Rie, J. Biochemistry and genetics of insect resistance to Bacillus thuringiensis. Annu. Rev. Entomol. 2002, 47, 501-533.

117. Loeza-Lara, P.D.; Benintende, G.; Cozzi, J.; Ochoa-Zarzosa, A.; Baizabal-Aguirre, V.M.; Valdez-Alarcón, J.J.; López-Meza, J.E. The plasmid pBMBt1 from Bacillus thuringiensis subsp. darmstadiensis (INTA Mo14-4) replicates by the rolling-circle mechanism and encodes a novel insecticidal crystal protein-like gene. Plasmid 2005, 54, 229-240.

118. Mesrati, L.A.; Tounsi, S.; Jaoua, S. Characterization of a novel vip3-type gene from Bacillus thuringiensis and evidence of its presence on a large plasmid. FEMS Microbiol. Lett. 2005, 244, 353-358.

119. Jensen, G.B.; Andrup, L.; Wilcks, A.; Smidt, L.; Poulsen, O.M. The aggregation-mediated conjugation system of Bacillus thuringiensis subsp. israelensis: Host range and kinetics of transfer. Curr. Microbiol. 1996, 33, 228-236.

120. Gammon, K.; Jones, G.W.; Hope, S.J.; Oliveira, C.M.F.; Regis, L.; Silva-Filha, M.H.; Dancer, B.M.; Berry, C. Conjugal transfer of a toxin-coding megaplasmid from Bacillus thuringiensis subsp. israelensis to mosquitocidal strains of Bacillus sphaericus. Appl. Environ. Microbiol. 2006, 73, 1766-1770.

121. Jarrett, P.; Stephenson, M. Plasmid Transfer between Strains of Bacillus thuringiensis Infecting Galleria mellonella and Spodoptera littoralis. Appl. Environ. Microbiol. 1990, 56, 1608-1614.

122. Thomas, D.J.I.; Morgan, J.A.W.; Whipps, J.M.; Saunders, J.R. Plasmid transfer between the Bacillus thuringiensis subspecies kurstaki and tenebrionis in laboratory culture and soil and in lepidopteran and coleopteran larvae. Appl. Environ. Microbiol. 2000, 66, 118-124.

123. Thomas, D.J.I.; Morgan, J.A.W.; Whipps, J.M.; Saunders, J.R. Plasmid transfer between Bacillus thuringiensis subsp. israelensis strains in laboratory culture, river water, and dipteran larvae. Appl. Environ. Microbiol. 2001, 67, 330-338.

124. González, J.M.; Brown, B.J.; Carlton, B.C. Transfer of Bacillus thuringiensis plasmids coding for delta-endotoxin among strains of B. thuringiensis and B. cereus. Proc. Natl. Acad. Sci. USA 1982, 79, 6951-6955.

125. Zhang, J.; Hodgman, T.C.; Krieger, L.; Schnetter, W.; Schairer, H.U. Cloning and analysis of the first cry gene from Bacillus popilliae. J. Bacteriol. 1997, 179, 4336-4341.

126. Yokoyama, T.; Tanaka, M.; Hasegawa, M. Novel cry gene from Paenibacillus lentimorbus strain semadara inhibits ingestion and promotes insecticidal activity in Anomala cuprea larvae. J. Invertebr. Pathol. 2004, 85, 25-32.

127. Barloy, F.; Delécluse, A.; Nicolas, L.; Lecadet, M.-M. Cloning and expression of the first anaerobic toxin gene from Clostridium bifermentans subsp. malaysia, encoding a new mosquitocidal protein with homologies to Bacillus thuringiensis delta-endotoxins. J. Bacteriol. 1996, 178, 3099-3105.

128. Rigden, D.J. Does distant homology with Evf reveal a lipid binding site in Bacillus thuringiensis cytolytic toxins? FEBS Lett. 2009, 583, 1555-1560. 
129. Costechareyre, D.; Dridi, B.; Rahbe, Y.; Condemine, G. Cyt toxin expression reveals an inverse regulation of insect and plant virulence factors of Dickeya dadantii. Environ. Microbiol. 2010, 12, 3290-3301.

130. Palma, L.; Muñoz, D.; Murillo, J.; Caballero, P. Draft Genome Sequence of Bacillus thuringiensis Serovar Tolworthi Strain Na205-3, an Isolate Toxic for Helicoverpa armigera. Genome Announc. 2014, 6, 1490-1504.

131. Murawska, E.; Fiedoruk, K.; Swiecicka, I. Modular genetic architecture of the toxigenic plasmid pIS56-63 harboring crylAb21 in Bacillus thuringiensis subsp. thuringiensis strain IS5056. Pol. J. Microbiol. 2014, 63, 147-156.

132. Wu, J.; Zhao, F.; Bai, J.; Deng, G.; Qin, S.; Bao, Q. Adaptive evolution of cry Genes in Bacillus thuringiensis: Implications for their specificity determination. Genomics Proteomics Bioinform. 2007, 5, 102-110.

133. Wu, J.; Zhao, F.; Bai, J.; Deng, G.; Qin, S.; Bao, Q. Evidence for positive Darwinian selection of vip gene in Bacillus thuringiensis. J. Genet. Genomics 2007, 34, 649-660.

134. Chungjatupornchai, W. Expression of the Mosquitocidal-Protein Genes of Bacillus thuringiensis Subsp israelensis and the Herbicide-Resistance Gene Bar in Synechocystis Pcc6803. Curr. Microbiol. 1990, 21, 283-288.

135. Bravo, A. Phylogenetic relationships of Bacillus thuringiensis delta-endotoxin family proteins and their functional domains. J. Bacteriol. 1997, 179, 2793-2801.

136. González, J.M., Jr.; Carlton, B.C. A large transmissible plasmid is required for crystal toxin production in Bacillus thuringiensis variety israelensis. Plasmid 1984, 11, 28-38.

137. Zghal, R.Z.; Jaoua, S. Evidence of DNA rearrangements in the 128-kilobase pBtoxis plasmid of Bacillus thuringiensis israelensis. Mol. Biotechnol. 2006, 33, 191-198.

138. Doggett, N.A.; Stubben, C.J.; Chertkov, O.; Bruce, D.C.; Detter, J.C.; Johnson, S.L.; Han, C.S. Complete genome sequence of Bacillus thuringiensis serovar israelensis strain HD-789. Genome Announc. 2013, 1, e01023-13.

139. Hu, X.; Fan, W.; Han, B.; Liu, H.; Zheng, D.; Li, Q.; Dong, W.; Yan, J.; Gao, M.; Berry, C.; et al. Complete genome sequences of the mosquitocidal bacterium Bacillus sphaericus $\mathrm{C} 3-41$ and comparisons with closely related Bacillus species. J. Bacteriol. 2008, 190, 2892-2902.

140. Poncet, S.; Bernard, C.; Dervyn, E.; Caylet, J.; Klier, A.; Rapoport, G. Improvement of Bacillus sphaericus toxicity against dipteran larvae by integration, via homologous recombination, of the Cry11A toxin gene from Bacillus thuringiensis subsp. israelensis. Appl. Environ. Microbiol. 1997, 63, 4413-4420.

141. Ben-Dov, E.; Zaritsky, A.; Dahan, E.; Barak, D.; Sinai, R.; Manasherob, R.; Khamraev, A.; Triotskaya, E.; Dubitsky, A.; Berezina, N.; et al. Extended screening by PCR for seven cry-group genes from field-collected strains of Bacillus thuringiensis. Appl. Environ. Microbiol. 1997, 63, 4883-4890.

142. Wang, J.; Boets, A.; van Rie, J.; Ren, G. Characterization of cry1, cry2, and cry9 genes in Bacillus thuringiensis isolates from China. J. Invertebr. Pathol. 2003, 82, 63-71.

143. Granero, F.; Ballester, V.; Ferre, J. Bacillus thuringiensis crystal proteins Cry1Ab and Cry1Fa share a high affinity binding site in Plutella xylostella (L.). Biochem. Biophys. Res. Commum. 1996, 224, 779-783. 
144. Li, H.; Gonzalez-Cabrera, J.; Oppert, B.; Ferre, J.; Higgins, R.A.; Buschman, L.L.; Radke, G.A.; Zhu, K.Y.; Huang, F. Binding analyses of Cry1Ab and Cry1Ac with membrane vesicles from Bacillus thuringiensis-resistant and -susceptible Ostrinia nubilalis. Biochem. Biophys. Res. Commun. 2004, 323, 52-57.

145. Hughes, P.A.; Stevens, M.M.; Park, H.-W.; Federici, B.A.; Dennis, E.S.; Akhurst, R. Response of larval Chironomus tepperi (Diptera: Chironomidae) to individual Bacillus thuringiensis var. israelensis toxins and toxin mixtures. J. Invertebr. Pathol. 2005, 88, 34-39.

146. Lee, M.K.; Curtiss, A.; Alcantara, E.; Dean, D.H. Synergistic effect of the Bacillus thuringiensis toxins CryIAa and CryIAc on the gypsy moth, Lymantria dispar. Appl. Environ. Microbiol. 1996, 62, 583-586.

147. Hernández-Rodríguez, C.S.; Boets, A.; van Rie, J.; Ferré, J. Screening and identification of vip genes in Bacillus thuringiensis strains. J. Appl. Microbiol. 2009, 107, 219-225.

148. Kuo, W.S.; Chak, K.F. Identification of novel cry-type genes from Bacillus thuringiensis strains on the basis of restriction fragment length polymorphism of the PCR-amplified DNA. Appl. Environ. Microbiol. 1996, 62, 1369-1377.

149. Liu, J.; Song, F.; Zhang, J.; Liu, R.; He, K.; Tan, J.; Huang, D. Identification of vip3A-type genes from Bacillus thuringiensis strains and characterization of a novel vip3A-type gene. Lett. Appl. Microbiol. 2007, 45, 432-438.

150. Palma, L.; Ruiz de Escudero, I.; Maeztu, M.; Caballero, P.; Muñoz, D. Screening of vip genes from a Spanish Bacillus thuringiensis collection and characterization of two novel Vip3 proteins highly-toxic to five lepidopteran crop pests. Biol. Control 2013, 66, 141-149.

151. Porcar, M.; Juárez-Pérez, V. PCR-based identification of Bacillus thuringiensis pesticidal crystal genes. FEMS Microbiol. Rev. 2003, 26, 419-432.

152. Tan, F.R.; Zhu, J.; Tang, J.; Tang, X.M.; Wang, S.Q.; Zheng, A.P.; Li, P. Cloning and characterization of two novel crystal protein genes, cry54Aal and cry30Fal, from Bacillus thuringiensis strain BtMC28. Curr. Microbiol. 2009, 58, 654-659.

153. Oppert, B.; Kramer, K.J.; Beeman, R.W.; Johnson, D.; McGaughey, W.H. Proteinase-mediated insect resistance to Bacillus thuringiensis toxins. J. Biol. Chem. 1997, 272, 23473-23476.

154. Sayyed, A.H.; Haward, R.; Herrero, S.; Ferre, J.; Wright, D.J. Genetic and biochemical approach for characterization of resistance to Bacillus thuringiensis toxin Cry1Ac in a field population of the diamondback moth, Plutella xylostella. Appl. Environ. Microbiol. 2000, 66, 1509-1516.

155. Mardis, E.R. Next-generation DNA sequencing methods. Annu. Rev. Genomics Hum. Genet. 2008, 9, 387-402.

156. Metzker, M.L. Sequencing technologies - The next generation. Nat. Rev. Genet. 2010, 11, 31-46.

157. Schuster, S.C. Next-generation sequencing transforms today's biology. Nat. Methods 2008, 5, $16-18$.

158. Shendure, J.; Ji, H. Next-generation DNA sequencing. Nat. Biotechnol. 2008, 26, 1135-1145.

159. Zhou, X.; Ren, L.; Meng, Q.; Li, Y.; Yu, Y.; Yu, J. The next-generation sequencing technology and application. Protein Cell 2010, 1, 520-536.

160. Hernandez, D.; Francois, P.; Farinelli, L.; Osteras, M.; Schrenzel, J. De novo bacterial genome sequencing: Millions of very short reads assembled on a desktop computer. Genome Res. 2008, $18,802-809$. 
161. Krampis, K.; Booth, T.; Chapman, B.; Tiwari, B.; Bicak, M.; Field, D.; Nelson, K.E. Cloud BioLinux: Pre-configured and on-demand bioinformatics computing for the genomics community. BMC Bioinform. 2012, 13, 42. doi:10.1186/1471-2105-13-42.

162. Zhang, W.Y.; Chen, J.J.; Yang, Y.; Tang, Y.F.; Shang, J.; Shen, B.R. A practical comparison of de novo genome assembly software tools for next-generation sequencing technologies. PLoS One 2011, 6, e17915.

163. Altschul, S.F.; Gish, W.; Miller, W.; Myers, E.W.; Lipman, D.J. Basic local alignment search tool. J. Mol. Biol. 1990, 215, 403-410.

164. Palma, L.; Muñoz, D.; Berry, C.; Murillo, J.; Ruiz de Escudero, I.; Caballero, P. Molecular and Insecticidal Characterization of a Novel Cry-Related Protein from Bacillus Thuringiensis Toxic against Myzus persicae. Toxins 2014, 6, 3144-3156.

165. Ye, W.; Zhu, L.; Liu, Y.; Crickmore, N.; Peng, D.; Ruan, L.; Sun, M. Mining new crystal protein genes from Bacillus thuringiensis based on mixed plasmid-enriched genome sequencing and a computational pipeline. Appl. Environ. Microbiol. 2012, 78, 4795-4801.

(C) 2014 by the authors; licensee MDPI, Basel, Switzerland. This article is an open access article distributed under the terms and conditions of the Creative Commons Attribution license (http://creativecommons.org/licenses/by/4.0/). 